\title{
UK Pension Fund Management After Myners: The Hunt for Correlation Begins
}

\author{
David Blake \\ Pensions Institute \\ Birkbeck College \\ London W1T 1LL \\ d.blake@bbk.ac.uk
}

March 2003

Dr David Blake is Professor of Financial Economics at Birkbeck College in the University of London and Chairman of Square Mile Consultants, a training and research consultancy. Senior Research Associate, Financial Markets Group, London School of Economics. Senior Consultant, UBS Pensions Research Centre, London School of Economics. Research Associate, Centre for Risk \& Insurance Studies, University of Nottingham Business School. Formerly Director of the Securities Industry Programme at City University Business School and Research Fellow at both the London Business School and the London School of Economics. He was a student at the London School of Economics in the 1970s and early 1980s, gaining his PhD on UK pension fund investment behaviour in 1986. In June 1996, he established the Pensions Institute at Birkbeck College (http://www.pensions-institute.org).

Key words: pension fund management, strategic asset allocation, liabilities, performance measurement, Myners Report, scheme-specific funding standard, statement of investment principles 


\begin{abstract}
The Myners Report will have a number of significant consequences for pension fund management and performance measurement in the UK.

It changes the way in which assets are selected. The strategic asset allocation will have overriding importance in pension fund management. Asset classes will be selected on the basis of their match with liabilities in terms of correlation and volatility, rather than on the basis of expected return. Every pension scheme will have a scheme-specific funding standard that reflects the maturity structure of the liabilities of the scheme.

It changes the role of the fund manager. A hierarchical relationship will develop between the investment advisor, actuary and fund manager. The investment advisory function assumes a primacy over the actuarial and fund management functions.
\end{abstract}

It changes the way investment performance is measured Liability-driven performance measurement and attribution will replace the existing performance measurement framework in the UK. The passively managed components of the pension fund will be judged on the costs of implementation. Only the performance of the surplus assets will be measured on a conventional basis.

The Myners Report is summarised and an illustrative statement of investment principles and transparency statement are presented. 


\section{Contents}

- Section

Page

Executive Summary

1. Introduction

2. Myners and the MFR

3. Fund Management after Myners

The Surplus

Surplus Risk

13

The Scheme-Specific Funding

Standard

13

Managing Surplus Risk

14

Managing Contribution Risk

4. The Roles of the Investment Advisor, Actuary and Fund Manager after

Myners

5. Performance Measurement after Myners

Liability-Driven Performance Benchmarks

Liability-Driven Performance Attribution

6. Illustration

Asset-Liability Management 25

Liability-Driven Performance Attribution

7. Conclusion

8. References

Appendix A

The Myners Report - A Summary of

Findings and Recommendations

Appendix B

Illustrative Statement of Investment Principles

Appendix E

The Optimal Strategic Asset

Allocation 


\section{Executive Summary}

\section{Myners and the MFR}

- Following the Myners Report on Institutional Investment in the UK, the Minimum Funding Requirement, introduced by the 1995 Pensions Act, will be replaced by a schemespecific funding standard and a regime of transparency and disclosure

- Annual transparency statements will be sent to members and the Statement of Investment Principles will be strengthened

- Investment objectives will have to be consistent with the need to deliver the pension promise

- The new regime is expected to come into force in 2005

\section{Fund Management after Myners}

- Defined benefit schemes are managed using asset-liability management

- The scheme-specific funding standard involves a strategic asset allocation that minimises a loss function of surplus and contribution risks

- Surplus risk is minimised by ensuring full funding on a continuous basis and matching as closely as possible the volatility of the assets and liabilities

- The volatility of the liabilities depends on the volatilities of real earnings growth, mortality, inflation, and interest rates. Of particular importance is the choice of discount factor and its volatility

- Contribution risk deals with the volatility of contributions into the pension scheme. It can be lowered by investing in lower volatility assets, but at the cost of raising average contributions

- The optimal asset allocation depends on the weight attached to contribution risk. As the pension fund matures, the weight in index-linked bonds will increase

\section{The Roles of the Investment Advisor, Actuary and Fund Manager after Myners}

- To avoid inconsistencies, the investment advisory function is separated from the actuarial and fund management functions. In future, pure fund management plays a subordinate role

- The length of the investment management contract is related to the actuarial valuation cycle 


\section{Performance Measurement after Myners}

- Liability-driven performance benchmarks replace peer-group benchmarks

- Possible benchmarks for final salary pension schemes include real earnings growth, price inflation, GDP growth, the growth rate in consumption expenditure in retirement and the discount rate for discounting future liabilities

- Liability-driven performance attribution (LPDA) is used for asset-liability managed portfolios

- The assets of a pension fund are divided between liability-driven assets and general assets that constitute the surplus in the fund

- The LPDA has four components: the rate of return on general assets, the rate of return on liability-driven assets due to stock selection, the rate of return on liability-driven assets due to market timing and the rate of return from a funding mismatch

\section{Illustration}

- We provide some illustrative pension fund asset allocations based on employer attitudes to surplus and contribution risk and historical correlations.

- Historical experience in the UK shows that the asset classes most highly correlated with pension liabilities are property, cash, and index-linked and international fixed-income bonds

- If it is believed that the future will be like the past, these assets will play a significant role in portfolios that minimise surplus and contribution risk.

- We show that current asset allocations in UK pension funds, dominated as they are by equity, do not minimise surplus and contribution risks.

- We stress that these results are purely illustrative and are not intended as a specific recommendation concerning future asset allocations. 


\section{Introduction}

Until the Myners Report, pension fund management in the UK had little in practice to do with the structure of pension liabilities. Despite paying lip service to asset-liability studies and so forth, pension fund investment was about the selection of investments that either maximised the expected return on the pension fund or was designed to beat some measure of the peer-group performance of other pension fund managers. Investment performance targets of the following kind were common: To exceed the 45th percentile of the CAPS Size Code A (the largest pension funds in the CAPS universe) cum property universe over rolling five-year periods. This meant investing in equities with their high historical returns and UK pension funds still have the highest weighting in equities of any pension funds in the world.

The Myners Report is going to lead to a radical change in pension fund investment in the UK. In will come instructions to choose strategic asset allocations that depend on both the characteristics of individual schemes and those schemes' sponsor's attitude to surplus and contribution risks. Asset classes will be chosen for their high degree of correlation with the growth rate in pension liabilities which, in turn, is linked to earnings growth.

These asset allocations are likely to be chosen by specialist investment advisors, rather than fund managers whose role is reduced to the subsidiary one of stock selection and market timing for the assets that constitute the surplus in schemes. The liability-driven assets will most likely be passively managed. Actuarial consultants cease to give investment advice and instead concentrate on valuing the liabilities and choosing the contribution rate into the scheme that is consistent with the optimal asset allocation that minimises the chances of scheme deficits emerging.

Performance measurement also changes. Out goes performance targets that seek to maximise return or beat the peer group. Liability-driven performance attribution (LPDA) becomes more common and pension fund assets are divided between liability-driven assets and the general assets that constitute the surplus in the fund. 


\section{Myners and the MFR}

In March 2001 the H M Treasury-sponsored review of institutional investment chaired by Paul Myners, chief executive of Gartmore, was published. Its recommendations were immediately accepted in full by the government (Department of Social Security and H M Treasury (2001)). The report called for a new approach to institutional investment, identified a series of current distortions to effective decision- making, and suggested ways of tackling them.

One of the key features of the report was its proposal to replace the Minimum Funding Requirement (MFR) for pension funds (introduced by the 1995 Pensions Act) with a long-term scheme-specific funding standard in the context of a strong regime of transparency and disclosure. The report also proposed a set of additional measures to strengthen protection:

- a recovery plan for returning schemes to full funding,

- a statutory duty of care on the scheme actuary,

- stricter conditions on the voluntary wind-up of a scheme where the employer remains solvent (e.g., the liabilities will have to include the actual cost of winding up the scheme and the actual cost of buying annuities to secure pensions in payment), and

- an extension of the fraud compensation scheme: the level of compensation for fraud will be increased to cover not simply the MFR liabilities as at present, but the full cost of securing members' accrued benefits (or the amount of the loss from fraud, whichever is the lesser).

The government argued that: 'These proposals will provide protection for members of all defined benefit schemes and will encourage an intelligent and thought-through approach to planning investment and contributions policy. They do not distort investment as the MFR does, because they do not involve the valuation of liabilities using statutory reference assets which create artificial incentives for schemes to invest in those assets. Employers that wish to go on offering defined benefit schemes will find it easier to do so under these proposals. At the same time, the proposals will make it more difficult for those that wish to walk away from the pension promises that they have made'.

\section{Transparency Statement}

Each year, every defined benefit pension fund would be required to publish a transparency statement that presents the following information:

- the current value of its assets and in what asset classes they were invested,

- the assumptions used to determine its liabilities,

- planned future contributions,

- its planned asset allocation for the following year or years, 
- the assumed returns and assumed volatilities of those returns for each asset class sufficient to meet the liabilities,

- a justification by the trustees of the reasonableness of both their asset allocation and the investment returns assumed in the light of the circumstances of the fund and of the sponsor, and

- an explanation of the implications of the volatility of the investment values for possible underfunding, and a justification by trustees of why this level of volatility is judged to be acceptable.

\section{The Importance of the Strategic Asset Allocation}

In respect of pension fund management, the report argued that the strategic asset allocation decision (the selection of key asset categories, such as cash, equities, bonds and property, as opposed to individual securities) was a significantly under-resourced activity. Empirical evidence (e.g., Blake, Lehmann and Timmermann (1999)) shows that the SAA dominates the investment performance of institutional investors.

\section{Clarity of Objectives and Timescale}

There was also a lack of clarity about objectives, with the objectives set having little apparent connection with the ultimate objective of the pension fund to deliver pensions to scheme members. A particularly unfortunate objective that pension funds have been set since the beginning of the 1980s is that of beating the peer-group median fund manager. Empirical evidence (e.g., Blake, Lehmann and Timmermann (2002)) indicates that this has encouraged herding by fund managers. Another issue relates to the timescale over which fund managers' performance is assessed. Trustees have come to expect long-term investment objectives to be met over very short horizons and this, in turn, has resulted in short-termism, the pressure on the companies in which fund managers invest to generate short-term profits at the expense of their own long-term investment programmes.

\section{Statement of the Principles of Institutional Investment}

The report made a number of proposals to deal with these distortions. The key proposal is the introduction of a statement of the principles of institutional investment ${ }^{1}$, incorporating a short set of clear principles of investment decision-making. In respect of the management of funds of defined benefit pension schemes, the statement should deal with the following issues:

- Where trustees elect to take investment decisions, they must have sufficient expertise to be able to evaluate critically any advice they take.

- Objectives for the overall fund should be clear and should not be expressed in terms which have no relationship to the fund's liabilities, such as performance relative to other pension funds, or to a market index.

\footnotetext{
${ }^{1}$ This is different from the statement of investment principles already required by the 1995 Pensions Act.
} 
- Strategic asset allocation decisions should receive a level of attention (and, where relevant, advisory or management fees) that fully reflect the contribution they can make towards achieving the fund's investment objective. Asset allocation should reflect the fund's own characteristics, not the average allocation of other funds.

- Trustees should agree with both internal and external investment managers an explicit written mandate covering agreement between trustees and managers on:

○ an objective for the fund, benchmark(s) and risk parameters that together with all the other mandates are coherent with the fund's aggregate objective and risk tolerances;

$\circ$ the manager's approach in attempting to achieve the objective; and

- clear timescale(s) of measurement and evaluation, such that the mandate will not be terminated before the expiry of the evaluation timescale other than for clear breach of the conditions of the mandate or because of significant change in the ownership or personnel of the investment manager. The mandate should not exclude the use of any set of financial instruments (e.g. private equity), without clear justification in the light of the specific circumstances of the fund.

- Trustees should consider whether the index benchmarks they have selected are appropriate and should arrange for measurement of the performance of the fund.

- A strengthened statement of investment principles, redesigned to improve transparency, should set out:

○ who is taking which decisions and why this structure has been selected;

$\circ$ the fund's investment objective;

○ the fund's planned asset allocation strategy, including projected investment returns on each asset class, and how the strategy has been arrived at;

$\circ$ the mandates given to all advisors and managers; and

$\circ$ the nature of the fee structures in place for all advisors and managers, and why this set of structures has been selected.

- There should be annual reporting of results with clear explanations as to why a fund deviated from the SIP if it did so.

Further details of the Myners' Report are given in Appendix A, an illustrative statement of investment principles is presented in Appendix B, while an illustrative transparency statement is presented in Appendix C.

Replacing the MFR requires primary legislation which is in the process of being drafted but is not expected to be implemented before 31 December 2004. In September 2001, the Department of Work and Pensions and H M Treasury (2001) announced some transitional measures, the most important of which were the extension to the deficit correction periods and the softening of the 
MFR equity market value adjustment test. Seriously underfunded schemes were given up to three years rather than just one to bring themselves up to $90 \%$ MFR, and all schemes were given up to ten years rather than five to bring themselves up to $100 \%$ MFR. In addition, the dividend yield in the MFR equity MVA was reduced from $3.25 \%$ to $3 \%$. Further, the requirement for annual recertification for schemes that are fully funded on an MFR test was removed.

Trustees and fund managers will have to start thinking of ways of implementing these changes over the next few months. In particular, they will have to pay considerable attention to:

- the determination of the strategic asset allocation that is most appropriate for the pension scheme whose assets are being managed,

- the setting of investment objectives, performance benchmarks and risk parameters that reflect the pension liabilities that will be delivered, and

- the determination of the timescale over which the objective is to be achieved

These factors are key inputs in asset-liability management strategies and in associated liabilitydriven performance benchmarks and attribution. We discuss these matters in the following sections. 


\section{Fund Management After Myners}

A funded pension scheme is composed of a pension fund plus a pension annuity. A fund accumulates from contribution inflows and the investment returns (both income and capital gains) on the assets purchased with those contributions. The values of these assets are subject to market fluctuations and this is known as investment risk. When a scheme member retires, he will receive a pension annuity that lasts for the remainder of his life.

Most workers in the UK have defined benefit $(D B)$ schemes in which the size of the pension benefit depends on factors such as final salary, length of pensionable service and age of member, rather than to the value of the assets in the fund. A typical UK scheme provides a pension equal to one-sixtieth $(1.67 \%)$ of final salary for each year of pensionable service up to a maximum of 40 years' service; thus the maximum pension is two-thirds of final salary. This pension is promised whether or not there are sufficient assets in the fund to pay the pension. The actuarial value of this promise aggregated across all scheme members constitutes the liabilities of the pension scheme. Since DB schemes are mainly provided by employers, it is the sponsoring employer of a DB scheme who therefore bears the investment risk.

If there are insufficient assets to pay the expected future pension in full, the pension scheme is said to be in actuarial deficit and the employer sponsoring the scheme is expected to restore the scheme to full funding by means of a series of deficiency payments over a specified period (currently 10 years), since the employer is expected to finance the pension scheme on a balance of cost basis. The actuarial deficit (where liabilities are measured as the actual cost of annuities for pensioner members and the cash equivalent transfer values on an MFR basis for active members) constitutes a debt on the employer for insolvency purposes and is equivalent to self-investment in the sponsoring employer's company. In extreme circumstances, where the sponsor cannot find the resources to make good the deficiency, the sponsor can close the fund or reduce wages in order to reduce its liabilities.

If there are more than sufficient assets to pay the pension in full, the pension scheme is said to be in actuarial surplus and the employer generally extracts this surplus using employer contribution holidays, although the trustees of the scheme might come under pressure to enhance benefits as well. The fortunes of the fund manager appointed by the trustees to manage the scheme assets will be highly correlated with the extent to which deficits or surpluses are created.

The appropriate investment management strategy for pension funds running DB schemes is assetliability management (ALM) (also called surplus risk management): see, e.g., Fabozzi and Konishi (1991) or Blake (2003, Ch.13).

\section{The Surplus}

The surplus is defined as the difference between the market value of the assets and the actuarial value of the liabilities:

$$
\text { Surplus }=\text { Assets }- \text { Liabilities }
$$

Liabilities are generally calculated using the projected unit method. The actuarial value of the pension liability for an active pension scheme member (assumed to be aged $t$ ) is usually 
calculated by the scheme actuary using the projected unit method on the basis of Guidance Note 9 (Retirement Benefits - Actuarial Reports) of the Faculty and Institute of Actuaries:

$$
\text { Liabilities }=a(t) \times W(t) \times R(t, T) \times P(t, T) \times A(T) \times D(t, T)
$$

where:

- $a(t)=$ Accrual factor for service by age $t$ (e.g., $5 / 60^{\text {th }}$ if the member has 5 years' service and the $60^{\text {th }}$ scale is used to determine the value of benefits).

- $W(t)=$ Pensionable salary at age $t$ (e.g. $£ 10,000$ ).

- $R(t, T)=$ Revaluation factor for earnings between age $t$ and retirement age $T(=1$ if there is no revaluation of earnings up until the retirement age, $=(1+g)^{(T-t)}$ if the revaluation rate $g$ is constant).

- $P(t, T)=$ Retention factor $=$ Probability of remaining in the scheme between age $t$ and retirement age $T$ : the two main reasons for a member not remaining in the scheme until retirement are death-in-service and leaving a scheme early as a result of changing jobs.

- $A(T)=$ Expected annuity factor (the present value of a life annuity of $£ 1$ per annum) at retirement age, $T: A(T)=p(T, T+1) /(1+r)+p(T, T+2) /(1+r)^{2}+p(T, T+3) /(1+r)^{3} \ldots$, where terms such as $p(T, T+1)$ are known as survival probabilities and indicate the probability of someone aged $T$ surviving to age $T+1$ etc., and $r$ is the real yield on the long-term bonds that are purchased by the insurance company and from which the pension payments are paid.

- $D(t, T)=$ Discount factor between age $t$ and retirement age $T\left(=1 /(1+r)^{(T-t)}\right.$ if the discount rate $r$ is constant).

To illustrate, suppose that we assume the following for a single male pension scheme member currently aged 35 and due to retire when he is 65 :

- $a(t)=5 / 60^{\text {th }}$

- $W(t)=£ 10,000$

- $R(t, T)=1.81$ (assuming earnings growth of $2 \%$ p.a. in real terms over the next 30 years to retirement)

- $P(t, T)=0.7$

- $A(T)=13.48$ (assuming mortality experience based on the PMA92 mortality table and a real yield of $2.5 \%$ on long-term government bonds)

- $D(t, T)=0.4767426$ (assuming a real discount rate of $2.5 \%$ and 30 years to retirement).

Then the actuarial value of the liabilities is $£ 6,784$ in respect of this member. 
This is explained as follows. The member's projected final salary is $£ 18,100(£ 10,000 \times 1.81)$ in real terms, and the member is expecting a pension of $5 / 60^{\text {th }}$ of his final salary or $£ 1,508$ (based on current service). This pension is payable for life. Based on the PMA92 mortality table, the pension fund will need to have accumulated $£ 13.48$ for each $£ 1$ of pension payable or $£ 20,328(£ 1,508 \times$ 13.48 ) by the time the member retires. The present value of this sum is $£ 9,691$. In other words, if we had $£ 9,691$ today and we invested it for 30 years at a real return of $2.5 \%$ p.a. (i.e., the same as the discount rate), we would have exactly the sum of money needed in 30 years' time to purchase a life annuity for the member paying £1,508 p.a. in real terms for life. However, suppose that, based on the past experience of the pension scheme, there is only a $70 \%$ chance that the member will still be in service by his normal retirement age (i.e., there is a $30 \%$ chance that the member dies or leaves service between 35 and 65 ). If we multiply $£ 9,691$ by $70 \%$ we get $£ 6,784$. The pension scheme is fully funded if it has assets with a market value of $£ 6,784$ for this active member.

\section{Surplus Risk}

Surplus risk (also called mismatch risk or shortfall risk) is defined as the standard deviation of the surplus and is equal to:

$$
\begin{aligned}
& \text { Surplus Risk }=\sqrt{ }\left[(\text { Standard deviation of the Assets })^{2}\right. \\
& +(\text { Standard deviation of the Liabilities })^{2} \\
& -2 \mathrm{x} \\
& \{\text { (Correlation between the Assets and Liabilities) } \\
& \mathrm{x} \text { (Standard deviation of the Assets) } \\
& \mathrm{x} \text { (Standard deviation of the Liabilities) \}] }
\end{aligned}
$$

Standard deviation and correlation are explained in Appendix D.

\section{The Scheme-Specific Funding Standard}

With ALM the aim is to select the fund's contribution rate and strategic asset allocation (SAA) over time in a way that minimises a weighted sum of surplus risk (3) and contribution risk, subject to the constraints that the surplus (1) is zero on the retirement date of the scheme member and never falls outside a specified range before retirement (see, e.g. Haberman and Sung (1994)):

Choose: Contribution Rate and Strategic Asset Allocation to:

Minimise: Loss Function $=$ Surplus Risk $+\lambda \times$ Contribution Risk

Subject to:

Surplus $=0$ on the retirement date

Surplus $\geq L B$ and $\leq U B$ before retirement

where $L B$ is the lower bound below which the surplus may not go and $U B$ is the upper bound. The weight $\lambda$ shows the relative importance to the employer of minimising contribution risk in 
comparison with minimising surplus risk: the higher the value of $\lambda$, the greater the relative importance of contribution risk in determining the optimal strategic asset allocation. It is the trustees' task to choose the value of $\lambda$, taking into account the employer's capacity to bear contribution risk.

The ALM exercise (4) involves two objectives and two instruments for achieving those objectives. Broadly speaking, the contribution rate is set and adjusted to ensure that the surplus always lies within permitted boundaries and the SAA is set and adjusted to minimise the following loss function that is specific to a particular pension scheme: surplus risk + $\lambda \times$ contribution risk. The SAA that minimises this loss function is the scheme-specific funding standard that replaces the MFR.

\section{Managing Surplus Risk}

To minimise surplus risk, the SAA is selected to match the pension liabilities in two key respects: size and volatility.

\section{- Ensuring Full Funding}

First, if pension schemes are always fully funded, so that assets are always sufficient to meet liabilities in full (implying Assets = Liabilities at all times), then it is clear from (1) that the surplus will always be zero. This is achieved by adjusting the contribution rate (especially the employer's contribution rate) into the fund to ensure that (1) always holds.

In practice, there are usually some tolerance limits around this equality. In the UK, for example, it is permissible for the value of assets to vary between $90 \%$ and $105 \%$ of the value of liabilities before remedial action needs to be taken, implying that the surplus cannot exceed $5 \%$ of the value of the liabilities $(U B=0.05 \times$ Liabilities) or fall below $-10 \%$ of the value of the liabilities ( $L B=$ $-0.1 \times$ Liabilities).

If the value of assets exceeds the $105 \%$ limit, the scheme has up to 5 years to reduce the value to $100 \%$ of liabilities (Social Security Act 1986). The most common means of doing this is the employer's contributions holiday, although other means are available: employee contributions holiday, improved pension benefits (i.e. raising Liabilities) or selling off financial assets (i.e. reducing Assets), the proceeds from which are returned to the sponsor subject to a $35 \%$ tax.

If the value of assets falls below $90 \%$ of the value of liabilities, the scheme has up to 3 years to raise the value to $90 \%$ of liabilities and a further 7 years to raise the value to $100 \%$ of liabilities (Pensions Act 1995, as amended by the Occupational Pension Schemes (Minimum Funding Requirement and Miscellaneous Amendments) Regulations 2001). The most common means of doing this is additional employer contributions (i.e. deficiency payments).

\section{- Matching Volatility}

Second, if it were possible for the assets in the pension fund to be selected in such a way that their aggregate volatility matches that of the liabilities, then it is clear from (3) that surplus risk could be reduced to zero. This requires the assets in the pension fund to have both the same volatility as 
the pension liabilities (Standard deviation of the Assets $=$ Standard deviation of the Liabilities) and to be perfectly correlated with them (Correlation between the Assets and Liabilities $=1$ ). In this case:

$$
\begin{aligned}
& \text { Surplus Risk }=\sqrt{ }\left[(\text { Standard deviation of the Liabilities })^{2}\right. \\
& +(\text { Standard deviation of the Liabilities })^{2} \\
& -2 \times\{(1) \times(\text { Standard deviation of the Liabilities) } \\
& \mathrm{x} \text { (Standard deviation of the Liabilities) }\} \text { ] } \\
& =\sqrt{ }\left[2 \times(\text { Standard deviation of the Liabilities })^{2}\right. \\
& \text { - } \left.2 \mathrm{x} \text { (Standard deviation of the Liabilities })^{2}\right] \\
& =0
\end{aligned}
$$

When surplus risk is zero, the value of the assets and liabilities will always go up and down exactly in line with each other.

\section{- The Volatility of the Liabilities}

In reality, however, assets do not exist with these precise characteristics. With existing assets, surplus risk can be reduced but not completely eliminated: the assets and liabilities will go up together and down together but not exactly in line. We can see why this is the case by examining the standard deviation of the liabilities in (2):

$$
\begin{aligned}
& \text { Standard deviation of the liabilities } \approx a(t) \times W(t) \times \\
& \qquad \begin{aligned}
\sqrt{ } & {\left[\{\bar{P} \times \bar{A} \times \bar{D} \times \text { Standard deviation of the revaluation factor } R(t, T)\}^{2}\right.} \\
& +\{\bar{R} \times \bar{A} \times \bar{D} \times \text { Standard deviation of the retention factor } P(t, T)\}^{2} \\
& +\{\bar{R} \times \bar{P} \times \bar{D} \times \text { Standard deviation of the annuity factor } A(T)\}^{2} \\
& \left.+\{\bar{R} \times \bar{P} \times \bar{A} \times \text { Standard deviation of the discount factor } D(t, T)\}^{2}\right]
\end{aligned}
\end{aligned}
$$

The definition (6) assumes that the factors determining the volatility of $R(t, T), P(t, T), A(T)$, and $D(t, T)$ are all independent of each other; mean values of variables are represented by bars over the variables. In (6), $a(t)$ and $W(t)$ are known at the time the calculation is made, so any volatility in the liabilities arises from volatility in the revaluation, retention, annuity and discount factors.

\section{The Volatility of the Revaluation Factor}

The standard deviation of the revaluation factor $R(t, T)$ depends on the volatility of the member's earnings between now and retirement. No financial asset presently exists to match this volatility perfectly. This is because no government or corporation has so far issued wage-indexed bonds, that is, bonds whose coupon and principal value are linked to national average earnings. Such bonds would provide a perfect matching asset for liabilities linked to average earnings growth, although they would provide a less than perfect match if the member's earnings did not grow exactly in line with national average earnings. The nearest financial instrument available for matching liabilities linked to earnings growth is a price-indexed bond (usually known as an indexlinked bond). This is because it is known that price inflation and wage inflation are highly correlated (Thornton and Wilson (1992)). 
But even if a pension fund held only index-linked bonds in its portfolio, it would still be exposed to productivity shocks. This follows from the relationship that determines wage inflation:

$$
\text { Wage inflation }=b_{1} \times \text { Price inflation }+b_{2} \times \text { Productivity growth }
$$

On average we would expect both price inflation and productivity improvements to be incorporated fully into earnings growth (i.e., we would expect $b_{1}=b_{2}=1$ ), although in slump conditions we might observe $b_{1}, b_{2}<1$, while in boom conditions we might observe $b_{1}, b_{2}>1$. Suppose, we set $b_{1}=b_{2}=1$, then it will be the case that (assuming price inflation and productivity growth are independent of each other and therefore uncorrelated):

$$
\begin{aligned}
& \text { Standard deviation of wage inflation }= \\
& \quad \text { Standard deviation of price inflation } \\
& + \text { Standard deviation of productivity growth }
\end{aligned}
$$

This indicates that an index-linked bond will perfectly match the pension scheme's exposure to price inflation, but leave it exposed to productivity shocks (i.e., the standard deviation of productivity growth). An unanticipated increase in the productivity of the workforce (say as result of a technological innovation) will raise their wages and hence the liabilities of the pension scheme, but this will not be matched by an increase in the value of the assets held in the fund.

\section{The Volatility of the Retention Factor}

The standard deviation of the retention factor $P(t, T)$ depends on the volatility of both staff turnover and death-in-service rates between now and retirement.

\section{The Volatility of the Annuity Factor}

The standard deviation of the annuity factor $A(T)$ depends in a highly complex manner on a combination of mortality risk, inflation risk and interest rate risk.

\section{Mortality Risk}

Mortality risk is the uncertainty attached to the survival probabilities, $p(T, T+1), p(T, T+2)$, etc. There has been an enormous improvement in mortality over the last 20 years which pension providers (such as insurance companies and pension schemes) have seriously underestimated. If pension providers underestimate the improvement in mortality, then the cost of providing a pension will be higher than was anticipated at the time that the member joined the scheme which might have been 40 years or more before the pension begins to be drawn.

\section{Inflation Risk}

When the pension becomes payable it should be matched with an instrument whose payouts replicate as closely as possible the underlying pension payments. Most pensions are subject to limited price indexation or LPI (i.e., retail price inflation up to a maximum of $5 \%$ p.a.), so the nearest available matching asset for this liability is an index-linked bond. In other words, the inflation risk associated with paying LPI pensions is minimised by holding index-linked bonds. (The perfect matching asset, the asset that reduces the inflation risk that faces the pension payer to zero, is an LPI bond.) 


\section{Interest Rate Risk}

Interest rate risk is the uncertainty attached to the yield curve. If there is an unanticipated fall in yields, then the cost of buying index-linked bonds rises. This is precisely what happened in the case of the guaranteed annuities offered by Equitable Life. Equitable Life sold deferred annuities with guaranteed high yields between 1957 and 1988, but it failed to hedge its exposure to interest rate risk. If interest rates fell, this would increase the cost of buying the bonds that are used to make the annuity payments. By the late 1990s, when the annuities started to get paid, interest rates had fallen to their lowest level for 40 years and Equitable Life found itself with insufficient reserves to pay the now very high cost of buying the requisite bonds.

\section{- The Choice of Discount Rate}

The choice of discount factor $D(t, T)$ in (2) (and in consequence its standard deviation in (6)) has been the subject of increasing disagreement in recent years. The nature of the disagreement can be expressed simply as follows. Should the discount rate reflect the liabilities to be paid, or should it reflect the pension fund's asset allocation? In other words, should the discount rate reflect the growth rate in liabilities, or should it reflect the weighted-average expected return on the assets in the pension fund?

If the discount rate is set to equal the growth rate $g$ in liabilities, then it is clear from (2) that:

$$
D(t, T)=1 /(1+g)^{(T-t)}=1 / R(t, T)
$$

in which case the value of liabilities in (2) reduces to:

$$
\begin{aligned}
\text { Liabilities } & =a(t) \times W(t) \times R(t, T) \times P(t, T) \times A(T) \times(1 / R(t, T)) \\
& =a(t) \times W(t) \times P(t, T) \times A(T)
\end{aligned}
$$

and the standard deviation of the liabilities in (6) reduces to:

$$
\begin{aligned}
& \text { Standard deviation of the liabilities } \approx \mathrm{a}(\mathrm{t}) \times \mathrm{W}(\mathrm{t}) \times \\
& \quad \begin{array}{l}
\sqrt{ }\left[\{\bar{A} \times \text { Standard deviation of the retention factor } P(t, T)\}^{2}\right. \\
\left.+\{\bar{P} \times \text { Standard deviation of the annuity factor } A(T)\}^{2}\right]
\end{array}
\end{aligned}
$$

So the only source of volatility that a pension fund need be concerned about is the volatility of the retention and annuity factors. However, as we indicated above, this is only a strictly legitimate procedure if the pension fund is fully invested in wage-indexed bonds. Some argue that pension liabilities should still be discounted in this manner even though such bonds do not exist.

Others argue that the discount factor should reflect the reality of the asset allocation that is actually adopted by the pension fund, in which case $r$ should equal the weighted-average expected return on the $N$ assets in the pension fund:

$$
r=\theta_{1} \times m_{1}+\theta_{2} \times m_{2}+\ldots+\theta_{N} \times m_{N}
$$


where

- $\theta_{1}=$ weight in the pension fund of asset 1 (e.g., $50 \%$ in UK equities), etc

- $m_{1}=$ expected real return on asset 1 (e.g., $4 \%$ for UK equities), etc.

If there is a significant equity component in the asset allocation of the pension fund, then the standard deviation of the discount rate could be quite high (since the volatility of equities is much higher than that of other assets) and could come to dominate the standard deviation of the liabilities itself.

\section{Managing Contribution Risk}

Contribution risk deals with the volatility of contributions into the scheme. If surplus risk is minimised, contributions into the scheme will be higher but more stable over time than if surplus risk is not minimised. Now employers usually like to have lower contributions than higher contributions.

But there is no free lunch. The only way to have lower average contributions is to invest more of the fund in equities and to accept greater surplus risk (i.e., a large fall in the value of the equities held in the pension fund that is not matched by a corresponding fall in the value of the liabilities) as a consequence. This, in turn, means that there will be greater contribution risk, i.e., contributions will be more volatile than if surplus risk is minimised. When the equity market is booming, there is likely to be an employer contribution holiday, but when the equity market slumps, there will be a scheme deficit that needs to be covered according to the MFR rules up to 31 December 2004 and the replacement rules thereafter. Furthermore, this call on the employer happens at a time when the employer's own share price is also likely to have fallen, a double whammy to the employer. The employer has to go to the market in an attempt to raise funds to put into his pension fund. If successful, the employer's gearing level might rise to dangerously high levels. If unsuccessful, the company itself could become insolvent.

So the trustees face a complex trade-off between surplus risk, contribution risk, and the expected level of contributions into the fund. A heavy investment in low volatility assets, such as cash, index-linked bonds and property, will lower surplus risk and contribution risk, but raise average contributions. A heavy investment in equities will raise surplus risk and contribution risk, but lower average contributions. It is this trade-off that turns the selection of the asset allocation of the pension fund from a purely technical exercise into one that must take account of the attitude of the employer, as the voluntary sponsor of the pension scheme, to both surplus risk and contribution risk.

The optimal strategic asset allocation for a pension fund is given in Appendix E. 


\section{The Roles of the Investment Advisor, Actuary and Fund Manager after Myners}

The introduction of a scheme-specific funding standard will radically change the relationship between the investment advisor, actuary and fund manager.

Under existing arrangements, pension schemes do not tend to have an independent investment advisor. The investment advisory function is carried out either by the scheme actuary (or consultant actuary) or, more commonly, by the fund manager. However, the absence of an independent investment advisor can lead to inconsistencies.

The task of valuing the liabilities and setting of the contribution rate is usually undertaken by the scheme actuary. A typical fund manager will generally not undertake his own actuarial valuation, but instead accept the valuation for the liabilities and the contribution rate determined by the scheme actuary as given. The fund manager's task is to recommend an asset allocation to the trustees, based on his assessment of the trustees' attitudes to surplus and contribution risk.

However, there is the potential for the decisions of the actuary to be inconsistent with those of the fund manager. The actuary typically chooses a contribution rate based on a notional asset allocation that he has selected without any reference to the attitude to risk of the trustees. The fund manager takes the contribution rate as given but then chooses an asset allocation that does reflect the attitude to risk of the trustees.

An inconsistency arises whenever the asset allocation chosen by the fund manager differs from the notional asset allocation chosen by the actuary. Suppose that the fund manager chooses a more defensive asset allocation than implied by the notional asset allocation. Surplus and contribution risk will be lower than for the notional portfolio, but the required contribution rate will be higher than the actual contribution rate into the fund, since the more defensive strategy is likely to generate a lower average return than assumed by the actuary. Eventually a deficit will emerge and this will have to be covered by higher contributions. The fund manager bears the risk of disappointing the trustees and sponsor over his performance, unless he has carefully explained the potential inconsistency and extracted higher contributions from the start.

The Myners Report recognises this potential inconsistency and recommends that schemes appoint an investment advisor, independent of both the actuary and fund manager. This could result in a hierarchical relationship between the investment advisor, actuary and fund manager. The investment advisor will determine the long-term strategic asset allocation, based on the employer's attitude to surplus and contribution risks. The actuary will take this strategic asset allocation and determine the required contribution rate, based on his calculation of pension scheme liabilities, since only actuaries are qualified to calculate a pension scheme's liabilities in (2) above.

The fund manager will be reduced to the subsidiary role of managing the surplus, i.e., making stock selection decisions and market timing or tactical asset allocation decisions relative to a longterm strategic asset allocation benchmark. Stock selection decisions deal with which particular securities to hold within a given asset class, e.g., whether to hold BT or C\&W within the equity class. Market timing or tactical asset allocation decisions involve short-run adjustments to the long-run SAA by temporarily reducing the weight in one asset class and increasing it in another, 
e.g., raising the weight in cash relative to equities because it is believed that the equity market is temporarily overvalued.

The loss function minimisation exercise (4) above determined both the SAA and the way in which the SAA changes over time as the fund matures. The SAA is therefore an essentially passive component of the investment management process, depending largely on the maturity structure of the liabilities. The key objective with the SAA is to implement and manage it passively at the lowest possible cost. The active components of the investment management process are the stock selection and market timing decisions. Fund managers use their research and skills to identify undervalued and overvalued securities (stock selection) and undervalued and overvalued sectors (market timing) and attempt to add value by constructing investment portfolios that are relatively overweight in what the fund managers believe are undervalued securities and sectors and are relatively overweight in what they believe to be overvalued securities and sectors. If they are correct in their beliefs, they will generate a higher return than if they merely picked the portfolio that reflected the current market consensus (known as the market portfolio). Furthermore, they will attempt to add value in this way without taking on excessive additional surplus risk. If, on the other hand, they are incorrect in their beliefs, they will lose value for the fund and may well do so in a way that increases the fund's surplus risk exposure.

Another issue concerns the length of investment management contracts. It seems natural that these should be related to the actuarial valuation cycle which is typically three years. So contract terms that are multiples of three years are likely to develop.

Another potential problem concerns the interpretation of measures of investment performance in the light of the technique. Asset-liability management justifies different pension funds pursuing different investment strategies. For example, small, fast-growing funds might pursue very aggressive investment strategies, while large mature funds might adopt passive investment strategies. As a result, single performance league tables drawn up on the assumption that all funds are pursuing the same objective of maximising returns are increasingly uninformative. This is discussed in the next section. 


\section{Performance Measurement after Myners}

In the light of the Myners Report, pension funds are likely to change their fund management strategy to one based on asset-liability management. A natural consequence of this is that performance benchmarks and performance attribution will also change to reflect the new emphasis on liabilities.

\section{Liability-Driven Performance Benchmarks}

For at least 20 years pension fund performance measurement in the UK has been dominated by peer-group benchmarks. More recently customised benchmarks that reflect the particular circumstances of the pension fund have become more common: by 2000 more than half of all UK pension funds had customised benchmarks. Following the Myners Report, the use of liabilitydriven performance benchmarks are likely to become much more prominent.

From the analysis above, we know that the liabilities of a final salary pension scheme depend on expected earnings growth; they also depend on forecasts of life expectancy and the discount rate used for discounting liabilities.

One natural benchmark would therefore be earnings growth or price inflation. A related benchmark might be GDP growth. Earnings growth and GDP growth are related in the long run, since the share of wages in national income does not trend significantly over time: in fact in longrun dynamic equilibrium, earnings growth and GDP growth will be the same. However, over the course of any business cycle, the growth rates in these two variables can differ substantially.

Another natural benchmark for pension funds would be the growth rate in consumption expenditure, since a pension scheme's primary purpose is to finance consumption expenditure in retirement. Strictly speaking the weights for the consumption expenditure index should reflect the pattern of expenditure by the elderly, which might have a higher weight in medical expenses and a lower weight in foreign holidays, say, than younger more active cohorts of the population. Again in long-run dynamic equilibrium, the growth rates in GDP and consumption expenditure will be the same (otherwise the savings ratio will tend towards either zero or unity).

The discount rate for discounting future liabilities provides another possible benchmark if it is set independently of the return on the assets in the fund. Some asset-liability models use the return on the assets in the fund as the discount rate for liabilities: obviously this could not be used as a benchmark. Others use the yield on long-term government or corporate bonds.

The justification for using a bond yield is that pension fund liabilities are less risky than equities and hence should be discounted at a lower yield. On the other hand, pension fund liabilities are not risk free, and so the discount rate should be higher than that on Treasury bills. This suggests that a bond yield provides an appropriate discount rate. The Faculty and Institute of Actuaries requires that a government bond yield is used to calculate (the first twelve years of) pension liabilities under the MFR. However, in November 2000, the Accounting Standards Board recommended using an AA corporate bond yield in Financial Reporting Standard 17 (FRS17). 


\section{Liability-Driven Performance Attribution}

Liability-driven performance attribution (LDPA) is the name given to the framework for identifying the sources of investment performance in the case of asset-liability managed portfolios (see, e.g., Blake (1998b)). It is one way of analysing the active-passive split.

We can illustrate the LDPA framework using the following balance sheet for an asset-liability managed pension fund:

\begin{tabular}{llll} 
Assets & \multicolumn{3}{c}{ Liabilities } \\
\hline Liability-driven assets & $B$ & Pension liabilities & $L$ \\
General assets & $E$ & Surplus & $S$ \\
\hline
\end{tabular}

Suppose that the pension liabilities $(L)$ constitute a predictable set of future cash outflows linked to inflation. The fund manager can meet these cash outflows by investing in index-linked bonds $(B)$ with the same pattern of cash flows; these bonds constitute the liability-driven assets (LDAs) in the balance sheet above. Suppose that the pension fund surplus $(S)$ is invested in general assets $(E)$. These can be any assets matching the risk-return preferences expressed by the pension scheme's sponsor (e.g. equities). The surplus is defined as assets $(B+E)$ minus liabilities $(L)$. The return on the surplus is defined as:

$$
r_{S} S=r_{E} E+r_{B} B-r_{L} L
$$

where

$r_{S}=$ rate of return on the surplus

$r_{E}=$ rate of return on the general assets

$r_{B}=$ rate of return on the liability-driven assets

$r_{L}=$ payout rate on the liabilities.

Both the pension liabilities and the liability-driven assets are sensitive to changes in interest rates. Higher interest rates reduce the present value of pension liabilities. Similarly, higher interest rates reduce the value of the index-linked bonds, since a given stream of coupon payments fixed in real terms is worth less today when yields on alternative assets are higher.

Assuming that interest rate risk is the only source of risk to this portfolio, we can use equation (13) to derive a decomposition of portfolio performance as follows. First, we rewrite the return on the general assets as:

$$
r_{E} E=r_{E} S+r_{E}(E-S)
$$

and the return on the liability-driven assets as:

$$
r_{B} B=r_{B} L+r_{B}(B-L)
$$

Then we can divide each side of (13) by $\mathrm{S}$ and substitute (14) and (15) to get the LDPA: 


$$
\begin{aligned}
r_{S} & =\frac{r_{E} S+r_{E}(E-S)}{S}+\frac{r_{B} L+r_{B}(B-L)}{S}-r_{L} \frac{L}{S} \\
& =r_{E}+\alpha\left(r_{B}-r_{L}\right)+\beta\left(r_{E}-r_{B}\right) \\
& =r_{E}+\alpha\left(r_{B}-\bar{r}_{B}\right)+\alpha\left(\bar{r}_{B}-r_{L}\right)+\beta\left(r_{E}-r_{B}\right)
\end{aligned}
$$

or:

$$
\begin{array}{ll}
\text { Rate of return on the surplus }=\quad \begin{array}{l}
\text { Rate of return on the general assets } \\
+
\end{array} \\
\text { Rate of return on the LDAs due to } \\
\text { security selection } \\
\text { + Rate of return on the LDAs due to market timing } \\
\text { + Rate of return from a funding mismatch }
\end{array}
$$

where:

$\alpha=\frac{L}{S}=$ financial leverage ratio

$\beta=\frac{L-B}{S}=\frac{E-S}{S}=$ funding mismatch ratio

$\bar{r}_{B}=$ expected return on bonds when they are correctly priced on the basis of the spot yield curve (i.e. when the future coupon payments are discounted using the appropriate spot yields) - see, e.g., Blake (2000, chapter 5).

The four-component LDPA in (16) can be explained as follows:

- The rate of return on general assets $\left(r_{E}\right)$. This can be analysed using standard techniques, e.g., comparing performance against a pre-agreed peer group or external benchmark.

- The rate of return on the liability-driven assets due to stock selection in terms of say credit quality management or sector management. This follows because $r_{B}$ is the actual return generated by the bonds chosen by the fund manager, whereas $\bar{r}_{B}$ is the benchmark return on the bonds if they were correctly priced according to the spot yield curve: $\left(r_{B}-\bar{r}_{B}\right)$ is therefore the excess return arising from the stock selection skills of the fund manager.

- The rate of return on the liability-driven assets due to market timing, that is, from choosing a portfolio of bonds with a maturity structure that differs from that of the underlying liabilities, thereby deliberately leaving the portfolio partially exposed to interest rate risk.

- The rate of return from a funding mismatch, that is, from active management of the liability-driven assets such that part of this category is invested in riskier general assets such as equities.

In the case where the surplus is exactly zero, the decomposition in (16) is not defined. The fund manager has just generated a sufficient return to meet the payout rate on liabilities. The LDPA in 
this case would be based on $r_{L}=r_{E}(E / L)+r_{B}(B / L)$ where $(E / L)$ is the portfolio weight in general assets and $(B / L)$ is the portfolio weight in liability-driven assets (see (13)). 


\section{Illustration}

\section{Asset-Liability Management}

We can illustrate how the optimal asset allocation (see (E.1) in Appendix E) might be determined using data on the returns on key asset classes over the period 1947-2000. Table 1 shows that equities had the highest real returns over the period and cash (represented by UK Treasury bills) the least. In between came property and bonds. Equities, especially UK equities, were also the most volatile assets, as measured by standard deviation (explained in Appendix D). Unsurprisingly, cash had the lowest volatility, but property, while having a higher average return than bonds, had a lower volatility. Property returns also had the highest correlation with the growth rate in liabilities (measured by real earnings growth) at 36\% (explained in Appendix D). The next highest was cash at $21 \%$. All the other asset classes had negative correlations with the liabilities, ranging from $-2 \%$ for international fixed-income bonds to a massive $-34 \%$ for UK fixed income bonds. UK index-linked bonds were also negatively correlated with earnings growth over the 20-year period of their existence, but this was compensated for by a low standard deviation and average returns almost as high as property. On the basis of the historical data given in Table $1^{2}$, we should not be surprised to find that property, cash, and index-linked and international fixed-income bonds would have played a significant role in portfolios that minimised the loss function in equation (4).

\begin{tabular}{lccc}
\hline Table 1: Historical Performance of Asset Classes, 1947-2000 & \\
Asset Class & $\begin{array}{c}\text { Mean } \\
\text { Real Return }\end{array}$ & $\begin{array}{c}\text { Standard } \\
\text { Deviation* }\end{array}$ & $\begin{array}{c}\text { Correlation with } \\
\text { Liabilities* }\end{array}$ \\
\hline UK Equities & $10 \%$ & $27 \%$ & $-5 \%$ \\
International Equities & $9 \%$ & $21 \%$ & $-5 \%$ \\
UK Index-Linked Bonds ${ }^{\$}$ & $4 \%$ & $7 \%$ & $-7 \%$ \\
UK Fixed-Income Bonds & $2 \%$ & $14 \%$ & $-34 \%$ \\
International Fixed-Income & $2 \%$ & $17 \%$ & $-2 \%$ \\
Bonds & $5 \%$ & $10 \%$ & $36 \%$ \\
Property & & $2 \%$ & $21 \%$ \\
Cash & $1 \%$ & $2 \%$ & $100 \%$ \\
UK Earnings & $2 \%$ & & \\
\hline
\end{tabular}

The returns on international equities and bonds are equal to the returns on US equities and bonds over the period. ${ }^{+}$Return in excess of inflation * See Appendix $\mathrm{D}{ }^{\$}$ The statistics for UK index-linked bonds are for the period 1982-2000 ${ }^{+}$Commercial and industrial

Sources: CSFB Equity-Gilt Study, Datastream, Financial Statistics, Investment Property Databank, Economic Trends Annual Supplement, Annual Abstract of Statistics, British Labour Statistics Historical Abstract 1886-

1968, British Economy Key Statistics 1900-1970, Global Financial Data.

The post-war period was an exceptional one for equity performance, generating the highest sustained real returns in recorded history. It is unlikely that such high real returns will be repeated in future. In the illustration below, we assume that asset classes have the same volatilities and

\footnotetext{
2 The correlations with liabilities in Table 1 differ markedly from those presented in a recent study by PricewaterhouseCooopers (2001). For example, the latter reports a correlation for index-linked bonds of $100 \%$ against $-7 \%$ in Table 1. The reason for the difference is that the PricewaterhouseCooopers study bases the total return on the index-linked bond on the book value which is uprated annually in line with inflation, whereas in Table 1 the market value of the bond is used. So Table 1 is consistent with the marking to market of the asset portfolio, while the PricewaterhouseCooopers study is not.
} 
correlation structures with liabilities as over the period $1947-2000^{3}$. However, we make the following assumptions about mean returns. The mean real return on equities is assumed to be $4 \%$, the equity risk premium is assumed to be $1.5 \%$ so that the real returns on all other assets is assumed to be $2.5 \%$. Except for cash which is assumed to have a real return of $1 \%$, the same as the historical average. Table 2 shows the performance data that we use in the illustration.

The second column of Table 3 shows the pension fund average strategic asset allocation for 2000 (denoted PFA2000 in the table). The portfolio was heavily invested in UK and international equities, with a combined weight in excess of $70 \%$. The next largest asset category was UK fixed-income bonds with a weighting of $13 \%$. Low weights (around 3\% each) were attached to cash, property and international bonds. The value of the loss function (4) (as a proportion of liabilities) was 0.6615 . The remaining columns of Table 3 present evidence demonstrating that the PFA2000 strategic asset allocation was not the minimum loss portfolio based on the performance parameters assumed in Table 2.

\begin{tabular}{lccc}
\hline $\begin{array}{l}\text { Table 2: Assumed Performance of Asset Classes } \\
\text { Asset Class }\end{array}$ & $\begin{array}{c}\text { Mean } \\
\text { Real Return }\end{array}$ & $\begin{array}{c}\text { Standard } \\
\text { Deviation* }\end{array}$ & $\begin{array}{c}\text { Correlation with } \\
\text { Liabilities* }^{*}\end{array}$ \\
\hline UK Equities & $4 \%$ & $27 \%$ & $-5 \%$ \\
International Equities & $4 \%$ & $21 \%$ & $-5 \%$ \\
UK Index-Linked Bonds & $2.5 \%$ & $7 \%$ & $-7 \%$ \\
UK Fixed-Income Bonds & $2.5 \%$ & $14 \%$ & $-34 \%$ \\
International Fixed-Income & $2.5 \%$ & $17 \%$ & $-2 \%$ \\
Bonds & $2.5 \%$ & $10 \%$ & $36 \%$ \\
Property & $1 \%$ & $2 \%$ & $21 \%$ \\
Cash & $2 \%$ & $2 \%$ & $100 \%$ \\
UK Earnings & &
\end{tabular}

Source: Table $1^{+}$Return in excess of inflation * See Appendix D

The third column presents the minimum loss portfolio in the case of $\lambda=0$ (the case for which the trustees and employer are not concerned about contribution risk at all) for the 35-year old male pension scheme member discussed above. The liabilities in respect of this member equalled $£ 6,784$. We assume that the pension scheme is fully funded in respect of this member and plans to remain so. This, in return, requires an aggregate contribution rate of $20 \%$ of the member's pensionable earnings, which we assume is divided $6 \%$ from the employee and $14 \%$ from the employer. The minimum loss portfolio in this case is heavily weighted in cash (53\%), UK indexlinked bonds (24\%) and property (15\%). Very little (just $7.5 \%$ ) is invested in UK equities, the principal current asset class of UK pension funds. Nothing at all is invested in either UK fixedincome bonds or international equities. There is a small weight $(0.5 \%)$ in international fixedincome bonds. The loss function for this portfolio is 0.6245 .

\footnotetext{
${ }^{3}$ It is important to recognise that although finance theory tells us the parameters, such as volatilities and correlations, that are needed to determine the optimal asset allocation (see (E.1)), it provides no guidance on how these should be estimated. In this analysis, we have based our estimates on annual returns over the last 50 years. Very different results might emerge if a different basis is used, e.g., three-year average returns over the last 20 years. Averages over periods longer than three years could be used, although this would be harder to justify given the three-year actuarial evaluation cycle.
} 


\begin{tabular}{|c|c|c|c|c|c|c|c|c|}
\hline \multicolumn{9}{|c|}{ Table 3: Strategic Asset Allocations } \\
\hline \multirow[t]{2}{*}{ Asset Class } & \multirow{2}{*}{$\begin{array}{r}\text { PFA } \\
2000\end{array}$} & \multicolumn{7}{|c|}{ Minimum Loss Portfolio as a Function of $\lambda$} \\
\hline & & o & 0.001 & 0.002 & 0.005 & 0.01 & 0.1 & $\mathbf{1 . 0}$ \\
\hline Cash & 3.0 & 53.0 & 41.8 & 35.6 & 26.8 & 20.6 & 13.3 & 12.4 \\
\hline UK Equities & 48.0 & 7.5 & 9.0 & 9.9 & 10.9 & 11.1 & 11.3 & 11.3 \\
\hline UK Property & 2.8 & 15.0 & 30.6 & 39.4 & 51.2 & 55.8 & 61.1 & 61.8 \\
\hline $\begin{array}{l}\text { UK Indexed-Linked } \\
\text { Bonds }\end{array}$ & 7.7 & 24.0 & 13.5 & 7.6 & 0 & 0 & 0 & 0 \\
\hline $\begin{array}{l}\text { UK Fixed- Income } \\
\text { Bonds }\end{array}$ & 13.2 & 0 & 0 & 0 & 0 & 0 & 0 & 0 \\
\hline Int. Equities & 22.2 & 0 & 0 & 0 & 0 & 0 & 0 & 0 \\
\hline $\begin{array}{l}\text { Int. Fixed-Income } \\
\text { Bonds }\end{array}$ & 3.1 & 0.5 & 5.1 & 7.5 & 11.1 & 12.5 & 14.3 & 14.5 \\
\hline Loss Function & 0.6615 & 0.6245 & 0.6126 & 0.6104 & 0.6076 & 0.6069 & 0.6063 & 0.6066 \\
\hline
\end{tabular}

Source: PALMOD. PFA2000 means the CAPS pension fund average portfolio for 2000

As $\lambda$ increases (implying increasing concern about contribution risk), we observe the following changes to the minimum loss portfolio: the weights in cash and UK index-linked bonds falls (for values of $\lambda$ equal to 0.005 or above, the weighting is zero), the weights in property and international bonds rise sharply, while there is a less steep increase in UK equity holdings. The overall minimum loss portfolio occurs when $\lambda$ takes the value of 0.1 and the loss function takes a value of 0.6063 . There are just four asset classes in this portfolio: property (61.1\%), international fixed income bonds (14.3\%), cash (13.3\%), and UK equities (11.3\%). The first three asset classes can be explained by their (relatively) high correlations with liabilities, while the last category is explained by its high real return. Most asset-liability models tend to produce a high weight in property, but this result is 'often suppressed by the programmer' (PricewaterhouseCoopers (2001, $\mathrm{p} 4)$ ).

The table shows that the minimum loss portfolio is very sensitive to values of $\lambda$ in the range 0 to 0.1 , but not sensitive to values of $\lambda$ above 0.1 . The last column of the table shows that the minimum loss portfolio when $\lambda=1$ is virtually identical to that when $\lambda=0.1$. The same is true for values of $\lambda$ above 1 .

Table 4 compares some properties of the distributions of the asset-liability ratio derived from a Monte Carlo simulation of two of the strategic asset allocations given in Table 3 using the asset return and volatility assumptions given in Table 2. The two SAAs are the PFA2000 and the global minimum loss portfolio (GMLP) (that for $\lambda=0.1$ ). The distribution is derived from 5000 simulations of three-year ahead pension fund asset values over three-year ahead liability values beginning from an initial asset-liability of unity (i.e., full funding or zero surplus) and a planned contribution rate of $20 \%$ of pensionable earnings. The three-year horizon corresponds with the typical interval between actuarial valuations in the UK.

The mean asset-liability ratio is near unity for both asset allocations, reflecting the fact that the contribution rate of $20 \%$ was set to maintain full funding over the three-year horizon. 


\begin{tabular}{lcr}
\hline $\begin{array}{l}\text { Table 4: Mean Three-Year Ahead Asset-Liability Ratios and } \\
\text { Values-at-Risk with Two Strategic Asset Allocations }\end{array}$ \\
\begin{tabular}{lcr} 
Ptatistic & PFA2000* & Global Minimum Loss Portfolio \\
& & $(\lambda=0.1)$ \\
\hline Mean & 0.99 & 1.00 \\
$1 \% \mathrm{VaR}$ & 0.62 & 0.68 \\
$5 \% \mathrm{VaR}$ & 0.73 & 0.76 \\
$20 \% \mathrm{VaR}$ & 0.87 & 0.87 \\
$50 \% \mathrm{VaR}$ & 1.05 & 1.03 \\
\hline
\end{tabular}
\end{tabular}

Source: PALMOD * UK pension fund average for 2000

The greater risk of the PFA2000 compared with the GMLP is evident from examining the extreme left-tail of the distribution. The $1 \%$ value-at-risk is 0.62 in the case of the PFA2000 and 0.68 in the case of the GMLP. This means that there is a $1 \%$ probability of the asset-liability ratio being less than 0.62 in the case of the PFA2000 and a 1\% probability of the asset-liability ratio being less than 0.68 in the case of the GMLP (see Appendix D). Chart 1 illustrates this graphically. To raise the $1 \% \mathrm{VaR}$ of the PFA2000 to equal that of the GMLP would require the contribution rate with the PFA2000 to rise by $9.7 \%$ (i.e., $0.68 / 0.62-1$ ) from $20 \%$ to $21.9 \%$. The VaRs are equal at the $20 \%$ level at 0.87 . Above the $20 \%$ level, the PFA2000 VaR exceeds the GMLP VaR. The median VAR is 1.05 with the PFA2000 and 1.03 with the GMLP, reflecting the higher expected return of the PFA2000 compared with the GMLP.

This illustration shows the trade-offs involved in setting a scheme-specific funding standard. The strategic asset allocation that minimises the loss function in (4), namely the GMLP, would help to reduce extreme negative outcomes, namely very low asset-liability ratios. Other strategic asset allocations with higher equity weighting and hence volatility, such as that currently typical of UK pension funds, namely the PFA2000, would require higher contributions than the GMLP in order to lower the probability of these extreme negative outcomes arising. However, the strategic asset allocations that have higher equity weightings, while having higher volatility, also have higher expected returns and hence generate higher median asset-liability ratios. The GMLP would need $2 \%$ (ie, 1.05/1.03 - 1) higher contributions than the PFA2000 in order to match the latter in terms of median asset-liability ratios 4 .

\footnotetext{
${ }^{4}$ It should be emphasised again that the strategic asset allocations reported in Table 3 are purely illustrative. They do not necessarily indicate how SAAs might look in the future, since the assumed performance parameters in Table 2 are based largely on a period of high inflation, lower international capital mobility and no euro. Nor are they intended to be critical of SAAs pre-Myners when pension funds were pursuing rather different objectives.
} 
Chart 1: 1\% VaR with the PFA2000 and GMLP Strategic Asset Allocations

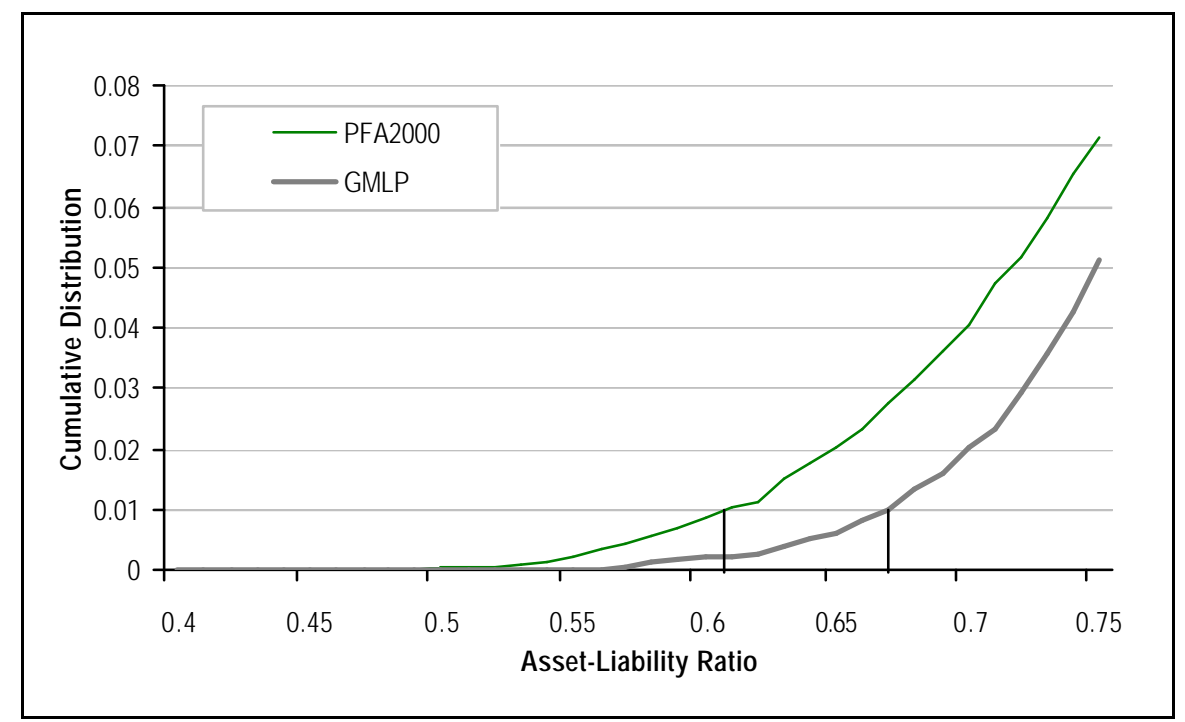

Source: PALMOD

\section{Liability-Driven Performance Attribution}

The LDPA can be illustrated using the following example. Suppose that a pension fund has the following balance sheet at the start and end of the year:

\begin{tabular}{lrrlrr} 
Assets & \multicolumn{2}{c}{ Liabilities } & Start year & End year \\
\hline Liability-driven assets $(B)$ & 6500 & 6689 & Pension liabilities $(L)$ & 6784 & 6967 \\
General assets $(E)$ & 600 & 634 & Surplus $(S)$ & 316 & 356 \\
Total & $\mathbf{7 1 0 0}$ & $\mathbf{7 3 2 3}$ & $\mathbf{7 1 0 0}$ & $\mathbf{7 3 2 3}$ \\
\hline
\end{tabular}

We will assume that the liability-driven assets are bonds, while the general assets are equities (and that equities have no yield curve effect).

We have the following returns on the components of the balance sheet:

\begin{tabular}{lcr} 
Component & $\begin{array}{r}\text { Realised rate of return } \\
(\%, \text { real })\end{array}$ & $\begin{array}{r}\text { Benchmark rate of return } \\
(\%, \text { real) }\end{array}$ \\
\hline Bonds & $r_{B}=2.90$ & $\bar{r}_{B}=2.50$ (assumption) \\
Equities & $r_{E}=5.67$ & $\bar{r}_{E}=6.00$ (assumption) \\
Liabilities & $r_{L}=2.70$ & \\
\hline
\end{tabular}

The realised rates of return are found by taking the difference between the end-of-year and startof-year values as a ratio of the start-of-year values. The benchmark return on bonds is calculated in a similar way but based on start- and end-year present values of coupon payments using appropriate spot yields. The benchmark return on equities is simply the realised return on a relevant index, e.g. the FT-A All Share Index. 
Using equation (16) with $\alpha=L / S=21.47$ and $\beta=(L-B) / S=0.899$ (using start-of-year values), the LDPA is determined as follows:

\begin{tabular}{lr} 
Component & Return $(\%$, real $)$ \\
\hline General assets $\left(r_{E}\right)$ & 5.67 \\
Security selection $\left(\alpha\left(r_{B}-\bar{r}_{B}\right)\right)$ & +8.59 \\
Market timing $\left(\alpha\left(\bar{r}_{B}-r_{L}\right)\right)$ & -4.29 \\
Funding mismatch $\left(\beta\left(r_{E}-r_{B}\right)\right)$ & +2.49 \\
Total & $\mathbf{1 2 . 4 6 \%}$ \\
\hline
\end{tabular}

The total real rate of return on the surplus of $12.46 \%$ is made up of $5.67 \%$ from the performance of the general assets, $8.59 \%$ from successful stock selection of the bond portfolio, $2.49 \%$ from a successful funding mismatch, and a loss of $4.29 \%$ from market timing. The security selection and market timing effects are magnified by a high leverage ratio $(\alpha)$ of 21.47 (the minimum permissible is 20 since the surplus may not (in the long term) exceed 5\% of liabilities), while the funding mismatch effect is magnified by a smaller funding mismatch ratio $(\beta)$ of 0.899 . The positive net return of $4.3 \%$ from active fund management (i.e., the sum of the returns from security selection and market timing) and the positive net return from a funding mismatch help to generate a high surplus return. However, this cannot conceal the fact that the fund manager underperformed the benchmark in terms of general assets by $0.33 \%$.

LDPA therefore tells us a great deal about the investment skills of the pension fund manager when he or she is constrained on the liability side of the balance sheet. The only additional information that is required over the current performance measurement framework is as follows: the present value of the pension liabilities (as determined by the pension scheme's actuary), together with the payout rate on these, and the value of liability-driven assets, together with a customised benchmark return on these.

LDPA is likely to become considerably more prominent following the introduction of schemespecific funding standards. In this new world, peer-group benchmarks will become far less significant and their use is likely to be confined to the 'general asset' category of pension fund portfolios. 


\section{Conclusion}

The Myners Report signalled the end of the Minimum Funding Requirement. This will have a number of significant consequences for pension fund management and performance measurement in the UK.

The strategic asset allocation will have overriding importance in pension fund management. Asset classes are likely to be selected on the basis of their match with liabilities in terms of volatility and correlation, rather than on the basis of expected return. Every pension scheme will have a schemespecific funding standard that reflects the maturity structure of the liabilities of the scheme.

Asset-liability management involves the minimisation of both surplus risk and contribution risk and the optimal asset allocation depends on the attitude of the employer to each type of risk. It is hard to predict how correlation patterns between asset returns and liabilities will develop in the future. However, if fund managers believe that correlation patterns in the future will be similar to those in the past, then the optimal asset allocation has a high weight in property, cash, indexlinked bonds and international fixed-income bonds and a corresponding low weight in equity, including private equity, and domestic fixed-income bonds.

It is important to take into account both the feasibility of a major switch in strategic asset allocations and the transitional consequences. Are there sufficient investment property and indexlinked bonds available for pension funds to switch into? What would happen to equity prices if all pension funds tried to sell their holdings at the same time? Table 5 indicates that UK pension funds with total asset holdings of around $£ 800$ bn would collectively find it difficult to make the switches in asset allocations (particularly into property and index-linked bonds) indicated above and high short-term volatility in asset prices could be expected as a result. Certainly higher returns on assets in high demand would attract additional supplies, but this could take time.

\begin{tabular}{|c|c|}
\hline \multicolumn{2}{|c|}{$\begin{array}{l}\text { Table 5: Market Capitalisation of Key UK Asset Classes at } 31 \\
\text { December } 2001\end{array}$} \\
\hline Asset Class & Market Capitalisation (£bn) \\
\hline UK Money Market Securities & 541 \\
\hline UK Fixed-Income Government Bonds & 204 \\
\hline UK Index-Linked Government Bonds & 71 \\
\hline $\begin{array}{l}\text { UK Fixed-Income Non-Government } \\
\text { Bonds* }\end{array}$ & 225 \\
\hline $\begin{array}{l}\text { UK Index-Linked Non-Government } \\
\text { Bonds* }\end{array}$ & 5 \\
\hline UK Equity & 1,482 \\
\hline UK Investment Property & 130 \\
\hline
\end{tabular}

Sources: HM Treasury, Debt Management Office, Merrill Lynch, London Stock Exchange, Investment Property Databank * Includes non-rated bonds

A hierarchical relationship is likely to develop between the investment advisor, actuary and fund manager. The investment advisor determines the strategic asset allocation, based on the employer's attitude to surplus and contribution risks. The actuary takes this strategic asset allocation and determines the required contribution rate, based on his calculation of pension scheme liabilities. The fund manager is reduced to the subsidiary role of security selection and market timing of the general assets that back the surplus in the pension scheme. The strategic asset allocation determined by the investment advisor will be implemented passively and at the 
lowest cost. The length of investment management contracts will be related to the actuarial valuation cycle which is typically three years.

Liability-driven performance measurement and attribution replaces the existing performance measurement framework in the UK. The minimisation of surplus and contribution risks implies that the investment performance of the fund manager will be judged against a scheme-specific or customised benchmark that reflects both the employer's attitude to these risks and the growth rate in the liabilities of each particular fund, rather than on relative performance against other fund managers. The passively managed components of the pension fund will be judged on the costs of implementation. Only the performance of the general assets is measured on a conventional basis in future.

The age of alchemy is over. Pension fund management in the UK is about to enter the scientific age. The hunt for correlation begins. 


\section{References}

Blake, D. (2003), Pension Schemes and Pension Funds in the United Kingdom, Oxford University Press, Oxford (second edition).

Blake, D. (1998a), Pension Schemes as Options on Pension Fund Assets: Implications for Pension Fund Management, Insurance: Mathematics \& Economics, 23, 263-86.

Blake, D. (1998b), Measuring the Performance of Pension Funds using Liability-Driven Performance Attribution, Journal of Pensions Management, 3, 105-9.

Blake, D. (2000), Financial Market Analysis, Wiley, Chichester.

Blake, D. (2002), PALMOD: Pension Asset-Liability Model (proprietary software)

Blake, D., Lehmann, B., and Timmermann, A. (1999), Asset Allocation Dynamics and Pension Fund Performance, Journal of Business, 72, 429-61.

Blake, D., Lehmann, B., and Timmermann, A. (2002), Performance Clustering and Incentives in the UK Pension Fund Industry, Journal of Asset Management, 3, 173-194.

Department of Social Security and H M Treasury (2001), Security for Occupational Pensions: The Government's Proposals, Department of Social Security and H M Treasury, London, March.

Department for Work and Pensions and H M Treasury (2001), The Minimum Funding Requirement: The Next Stage of Reform, London, September (also contains the Occupational Pension Schemes (Minimum Funding Requirement and Miscellaneous Amendments) Regulations 2001).

Fabozzi, F. and Konishi, A. (eds) (1991), Asset-Liability Management, Probus, Chicago.

Haberman, S., and Sung, JH. (1994), Dynamic Approaches to Pension Funding, Insurance: Mathematics \& Economics, 15, 151-62.

HM Treasury and Department for Work and Pensions (2001), Myners Review of Institutional Investment in the UK: The Government's Response, London, October.

Mood, A., Graybill, F., and Boes, D. (1974), Introduction to the Theory of Statistics, McGrawHill Kogakusha, Tokyo.

Myners, P. (2001), Institutional Investment in the United Kingdom: A Review, HM Treasury, London, March.

PricewaterhouseCoopers (2001), Pension Fund Investment, Pensions Briefing, October.

Samuelson, P.A. (1989), A Case at Last for Age-Phased Reduction in Equity, Proceedings of the National Academy of Science, Vol. 86, Washington, DC, 9048-9051. 
Thornton, P.N., and Wilson, A.F. (1992), A Realistic Approach to Pension Funding, Journal of the Institute of Actuaries, 119, 229-312. 


\section{Appendix A: The Myners Report - A Summary of Findings and Recommendations}

The Myners Report (Institutional Investment in the United Kingdom: A Review) was published on 6 March 2001. In introducing his report, Paul Myners said:

Our funded pensions system, our highly-developed equity culture and the professionalisation of investment in the UK are an enviable success story. I pay tribute to the commitment and dedication of institutions and their advisors in bringing this about. Nevertheless, the industry and its decision-taking structures face forbidding challenges: an ageing population, unrecognisably different labour markets, shifting employer attitudes. In the world we now face, an ever-higher premium is likely to be placed on efficiency and flexibility. The review finds that savers' money is too often being invested in ways that do not maximise their interests. It is likely to follow too that capital is being inefficiently allocated in the economy. The review sets out a blueprint for change, to drive clearer incentives and tougher customer pressures throughout the savings and investment industry.

\section{The report identified the following main distortions:}

- Pension fund trustees, who are the very centre of the system, are being asked to take crucial investment decisions, yet many lack resources and expertise. They are often unsupported by in-house staff, and are rarely paid.

- As a result, the trustees rely heavily on a narrow group of investment consulting (mainly actuarial) firms for advice. Such firms are small in number, have a narrow range of expertise and little room for specialisation. Furthermore, their performance is not usually assessed or measured.

- A particular consequence of the present structure is that asset allocation (the selection of which markets, as opposed to which individual stocks, to invest in) is an under-resourced activity. This is especially unfortunate given the weight of academic evidence suggesting that these decisions can be critical determinants of investment performance.

- A lack of clarity about objectives at a number of levels. Fund managers are being set objectives which, taken together, appear to bear little coherent relationship to the ultimate objective of the pension fund, namely to meet its pension obligations.

- Fund managers are often set objectives which give them unnecessary and artificial incentives to herd. So-called peer-group benchmarks, directly incentivising funds to copy other funds, remain common. Risk controls for active managers are increasingly set in ways which give them little choice but to cling closely to stock market indices, making meaningful active management near-impossible.

- There is also extreme vagueness about the timescales over which fund managers' performance is to be judged. This is a real (but wholly unnecessary) cause of shorttermism in fund managers' approach to investment. 
- Fund managers remain unnecessarily reluctant to take an activist stance in relation to corporate underperformance, in companies where they own substantial shareholdings, even where this would be in their clients' financial interests.

- Finally, an important cost to pension funds, namely broking commission, is subject to insufficient scrutiny. Clearer and more rigorous disciplines could be applied to these costs, which are substantial.

- In the life insurance industry, competition, though intense, tends not to focus directly on investment performance, and this issue needs to be tackled if stronger incentives to efficient investment decision- making in the industry are to be created.

The report made a number of proposals to deal with these distortions. The key proposal is the introduction of a statement of the principles of institutional investment, incorporating a short set of clear principles of investment decision-making. The idea is modelled on the approach taken on corporate governance by the Cadbury (and later) codes. These principles would apply first to pension funds and subsequently to other institutional investors. As with the Cadbury code, they would not be mandatory. However, where a pension fund chose not to comply with them, it would have to explain to its members why not.

The set of principles proposed for defined benefit pension schemes is as follows (as revised in the Government's Response to the Myners Review, October 2001):

- Effective decision-making. Decisions should be taken only by persons or organisations with the skills, information and resources necessary to take them effectively. Where trustees elect to take investment decisions, they must have sufficient expertise and appropriate training to be able to evaluate critically any advice they take. Trustees should ensure that they have sufficient in-house staff to support them in their investment responsibilities. Trustees should also be paid, unless there are specific reasons to the contrary. It \& good practice for trustee boards to have an investment subcommittee to provide the appropriate focus. Trustees should assess whether they have the right set of skills, both individually and collectively, and the right structures and processes to carry out their role effectively. They should draw up a forward-looking business plan The Government will give legal effect to this principle by imposing a duty of care on trustees, requiring them to be familiar with investment matters when they take investment decisions.

- Clear objectives. Trustees should set out an overall investment objective for the fund that:

- $\quad$ represents their best judgement of what is necessary to meet the fund's liabilities given their understanding of the contributions likely to be received from employer(s) and employees; and

- takes account of their attitude to risk, specifically their willingness to accept underperformance due to market conditions.

Objectives for the overall fund should not be expressed in terms which have no relationship to the fund's liabilities, such as performance relative to other pension funds, or to a market index. 
- Focus on asset allocation. Strategic asset allocation decisions should receive a level of attention (and, where relevant, advisory or management fees) that fully reflect the contribution they can make towards achieving the fund's investment objective. Decisionmakers should consider a full range of investment opportunities, not excluding from consideration any major asset class, including private equity. Asset allocation should reflect the fund's own characteristics, not the average allocation of other funds.

- Expert advice. Contracts for actuarial services and investment advice should be opened to separate competition. The fund should be prepared to pay sufficient fees for each service to attract a broad range of kinds of potential providers.

- Explicit mandates. Trustees should agree with both internal and external investment managers an explicit written mandate covering agreement between trustees and managers on:

- $\quad$ an objective, benchmark(s) and risk parameters that together with all the other mandates are coherent with the fund's aggregate objective and risk tolerances;

- the manager's approach in attempting to achieve the objective; and

- $\quad$ clear timescale(s) of measurement and evaluation, such that the mandate will not be terminated before the expiry of the evaluation timescale for underperformance alone.

The mandate and trust deed and rules should not exclude the use of any set of financial instruments, without clear justification in the light of the specific circumstances of the fund. Trustees, or those to whom they have delegated the task, should have a full understanding of the transaction-related costs they incur, including commissions. They should understand all the options open to them in respect of these costs, and should have an active strategy - whether through direct financial incentives or otherwise - for ensuring that these costs are properly controlled without jeopardising the fund's other objectives. Trustees should not without good reason permit soft commissions to be paid in respect of their fund's transactions.

- Activism. The mandate and trust deed should incorporate the principle of the US Department of Labor Interpretative Bulletin on activism. Trustees should also ensure that managers have an explicit strategy, elucidating the circumstances in which they will intervene in a company; the approach they will use in doing so; and how they measure the effectiveness of this strategy. The US Department of Labor Interpretative Bulletin 26 on activism is as follows:

- $\quad$ The fiduciary act of managing plan assets that are shares of corporate stock includes the voting of proxies appurtenant to those shares of stock.

- The fiduciary obligations of prudence and loyalty to plan participants and beneficiaries require the responsible fiduciary to vote proxies on issues that may affect the value of the plan's investment.

- An investment policy that contemplates activities intended to monitor or influence the management of corporations in which the plan owns stock is consistent with a 
fiduciary's obligations under ERISA (1974 Employee Retirement Income Security Act) when the responsible fiduciary concludes that there is a reasonable expectation that activities by the plan alone, or together with other shareholders, are likely to enhance the value of the plan's investment, after taking into account the costs involved. Such a reasonable expectation may exist in various circumstances, for example, where plan investments in corporate stock are held as long-term investments or where a plan may not be able to easily dispose such an investment.

- Active monitoring and communication activities would generally concern such issues as the independence and expertise of candidates for the corporation 's board of directors and assuring that the board has sufficient information to carry out its responsibility to monitor management. Other issues may include such matters as consideration of the appropriateness of executive compensation, the corporation's policy regarding mergers and acquisitions, the extent of debt financing and capitalisation, the nature of long-term business plans, the corporation's investment in training to develop its workforce, other workplace practices and financial and non-financial measures of corporate performance. Active monitoring and communication may be carried out through a variety of methods including by means of correspondence and meetings with corporate management as well as by exercising the legal rights of a shareholder.

- Appropriate benchmarks. Trustees should:

- $\quad$ explicitly consider, in consultation with their investment manager(s), whether the index benchmarks they have selected are appropriate; in particular, whether the.construction of the index creates incentives to follow sub-optimal investment strategies;

- if setting limits on divergence from an index, ensure that they reflect the approximations involved in index construction and selection;

- consider explicitly for each asset class invested, whether active or passive management would be more appropriate given the efficiency, liquidity and level of transaction costs in the market concerned; and

- where they believe active management has the potential to achieve higher returns, set both targets and risk controls that reflect this, giving the managers the freedom to pursue genuinely active strategies.

- Performance measurement. Trustees should arrange for measurement of the performance of the fund and make formal assessment of their own procedures and decisions as trustees. They should also arrange for a formal assessment of performance and decision-making delegated to advisors and managers.

- Transparency. A strengthened Statement of Investment Principles should set out:

- who is taking which decisions and why this structure has been selected; 
- the fund's investment objective;

- the fund's planned asset allocation strategy, including projected Investment returns on each asset class, and how the strategy has been arrived at;

- $\quad$ the mandates given to all advisors and managers; and

- $\quad$ the nature of the fee structures in place for all advisors and managers, and why this set of structures has been selected.

- Regular reporting. Trustees should publish their Statement of Investment Principles and the results of their monitoring of advisors and managers. They should send key information from these annually to members of these funds, including an explanation of why the fund has chosen to depart from any of these principles.

\section{The following principles are proposed for defined contribution schemes:}

- Effective decision-making. Decisions should only be taken by persons or organisations with the skills, information and resources necessary to take them effectively. Where trustees elect to take investment decisions, they must have sufficient expertise and appropriate training to be able to evaluate critically any advice they take. Where scheme members are given a choice regarding investment issues, sufficient information should be given to them to allow an appropriate choice to be made. Trustees should ensure that they have sufficient in-house staff to support them in their investment responsibilities. Trustees should also be paid, unless there are specific reasons to the contrary. It is good practice for trustee boards to have an investment subcommittee to provide appropriate focus. Trustees should assess whether they have the right set of skills, both individually and collectively, and the right structures and processes to carry out their role effectively. They should draw up a forward-looking business plan.

- Clear objectives. In selecting funds to offer as options to scheme members, trustees should:

- $\quad$ consider the investment objectives, expected returns, risks and other relevant characteristics of each fund, so that they can publish their assessments of these characteristics for each selected fund; and

- $\quad$ satisfy themselves that they have taken their members' circumstances into account, and that they are offering a wide enough range of options to satisfy the reasonable return and risk combinations appropriate for most members.

- Focus on asset allocation. Strategic asset allocation (for example for default and lifestyle options) should receive a level of attention (and, where relevant, advisory or management fees) that fully reflects the contribution they can make to achieving investment objectives. Decision-makers should consider a full range of investment opportunities, not excluding from consideration any major asset class, including private equity. 
- Choice of default fund. Where a fund is offering a default option to members through a customised combination of funds, trustees should make sure that an investment objective is set for the option, including expected returns and risks.

- Expert advice. Contracts for investment advice should be open to competition, and fee rather than commission based. The scheme should be prepared to pay sufficient fees to attract a broad range of kinds of potential providers.

- Explicit mandates. Trustees should communicate to members, for each fund offered by the scheme:

- the investment objective for the fund, its benchmark(s) and risk parameters; and

- the manager's approach in attempting to achieve the objective.

These should also be discussed with the fund manager concerned, as should a clear timescale(s) of measurement and evaluation, with the understanding that the fund mandate will not be terminated before the expiry of the evaluation timescale for underperformance alone. Trustees, or those to whom they have delegated the task, should have a full understanding of the transaction-related costs they incur, including commissions. They should understand all the options open to them in respect of these costs, and should have an active strategy - whether through direct financial incentives or otherwise - for ensuring that these costs are properly controlled without jeopardising the fund's other objectives. Trustees should not without good reason permit soft commissions to be paid in respect of their fund's transactions.

- Activism. The mandate and trust deed should incorporate the principle of the US Department of Labor Interpretative Bulletin on activism. Managers should have an explicit strategy, elucidating the circumstances in which they will intervene in a company; the approach they will use in doing so; and how they measure the effectiveness of this strategy.

- $\quad$ Appropriate benchmarks. Trustees should:

- explicitly consider, in consultation with their investment manager(s), whe ther the index benchmarks they have selected are appropriate; in particular, whether the construction of the index creates incentives to follow sub-optimal investment strategies;

- if setting limits on divergence from an index, ensure that they reflect the approximations involved in index construction and selection;

- consider explicitly for each asset class invested, whether active or passive management would be more appropriate given the efficiency, liquidity and level of transaction costs in the market concerned; and

- where they believe active management has the potential to achieve higher returns, set both targets and risk controls that reflect this, giving managers the freedom to pursue genuinely active strategies. 
- $\quad$ Performance measurement. Trustees should arrange for measurement of the performance of the funds and make formal assessment of their own procedures and decisions as trustees. They should also arrange for a formal assessment of performance and decisionmaking delegated to advisors and managers.

- Transparency. A strengthened Statement of Investment Principles should set out:

- $\quad$ who is taking which decisions and why this structure has been selected;

- $\quad$ each fund option's investment characteristics;

- the default option's investment characteristics, and why it has been selected;

- $\quad$ the agreements with all advisors and managers; and

- the nature of the fee structures in place for all advisors and managers, and why this set of structures has been selected.

- Regular reporting. Trustees should publish their Statement of Investment Principles and the results of their monitoring of advisors and managers. They should send key information from these annually to members of these funds, including an explanation of why the fund has chosen to depart from any of these principles.

In commenting on the proposed set of principles, Paul Myners said: 'The principles may seem little more than common sense. In a way they are - yet they certainly do not describe the status quo. Following them would require substantial change in decision-making behaviour and structures.' The report called for the industry to adopt the principles voluntarily within two years, but if necessary the government should legislate to require disclosure against them. The Government expects pension funds to disclose publicly their compliance with these principles on a voluntary basis. Insured schemes are excluded from the set of principles and other small schemes can explain why they have not implemented a particular principle (e.g., cost of compliance).

\section{The review made a series of other proposals. The main ones relate to:}

- $\quad$ Minimum Funding Requirement. The replacement of the MFR with a regime based of transparency and disclosure, under which pension funds would report publicly on the current financial state of the fund and on future investment plans. Each year, every defined benefit pension fund would be required to publish:

- the current value of its assets and in what asset classes they were invested;

- $\quad$ the assumptions used to determine its liabilities;

- $\quad$ planned future contributions;

- $\quad$ its planned asset allocation for the following year or years; 
- $\quad$ the assumed returns and assumed volatilities of those returns for each asset class sufficient to meet the liabilities;

- $\quad$ a justification by the trustees of the reasonableness of both their asset allocation and the investment returns assumed in the light of the circumstances of the fund and of the sponsor; and

- $\quad$ an explanation of the implications of the volatility of the investment values for possible underfunding, and a justification by trustees of why this level of volatility is judged to be acceptable.

- $\quad$ Pension fund surpluses. The Law Commission to be asked whether it can suggest greater legal clarity around the ownership of surplus pension fund assets. The Finance Act 2001 reduced the rate of tax on distributed pension fund surpluses from $40 \%$ to $35 \%$.

- $\quad$ Private equity. Investment in private equity should benefit from the framework set out by the principles and from the replacement of the MFR. The review also made a number of proposals which take account of the special nature of private equity as an asset class for institutional investors, including changes to the maximum number of partners in a limited partnership and change s to the taxation of investments in limited partnerships. It also calls for the British Venture Capital Association to take action to improve transparency and disclosure about issues such as investment returns and compensation. The Government announced the introduction of Regional Venture Capital Funds.

- $\quad$ Compensation. The level of compensation provided by the Pensions Compensation Board for non-pensioner members should be increased to cover not simply the 90 per cent of MFR liabilities as at present, but something closer to the cost of securing members' accrued rights (or the amount of the loss, whichever is the lesser).

- Independent custody. There should be a statutory requirement for funds to have independent custody of assets. 


\section{Appendix B: Illustrative Statement of Investment Principles}

The Pensions Act 1995 requires trustees to prepare, publish and maintain a statement of investment principles (SIP) that governs the selection and management of their scheme's investments. In preparing the SIP the trustees are required to take written advice from 'a person who is reasonably believed by the trustees to be qualified by his ability in and practical experience of financial matters and to have the appropriate knowledge and experience of the management of the investment of such schemes'. However, they are not compelled to act on the basis of that advice. They must also consult the employer, but do not need the consent of the employer to undertake specific investments.

Trustees should publish the SIP and the results of their monitoring of advisors and managers and send them annually to members of the fund. The Statement should explain why a fund has decided to depart from any of these principles. Section 35 of the Act specifies the issues that must be covered in the SIP.

\section{Investment Objectives of the Pension Fund}

The trustees' duty is to act in the best financial interests of scheme members and to choose the level of contributions and asset allocation most appropriate for securing in full the benefits promised by the scheme, taking account of the employer's attitude towards the volatility of contributions.

The trustees have ascertained that the employer values a high degree of stability in the contribution rates into the scheme

Accordingly, the investment advisors appointed by the trustees to determine the pension fund's strategic asset allocation are instructed to:

- Give primary consideration to the liability-matching prospects of any asset class they recommend.

- $\quad$ Take account of the employer's wish for highly stable contribution rates.

In turn, the investment managers appointed by the trustees are set the following investment performance targets:

- $\quad$ To implement the strategic asset allocation recommended by the investment advisors and approved by the trustees at the lowest cost to the scheme.

- In respect of non-liability-driven assets held in the scheme: to exceed the benchmark return on each asset class by X\% p.a. over the term of the investment mandate.

\section{- Mandates and Fee Structures}

\section{Who Takes Decisions and Why This Structure Has Been Selected}

The trustees retain overall power of investment in relation to the fund but may from time to time delegate to an investment committee the power to decide the investment policy of the fund. The investment committee consists of trustees who have been trained in investment matters (although 
none is currently qualified as an 'approved person' to give explicit investment advice). The investment committee is required to notify the trustees of its decisions concerning the investment policy of the fund. Any changes in the investment policy shall be notified to the trustees on a quarterly basis.

- $\quad$ The investments of the fund are currently managed by one index tracking manager (ABC), one specialist property manager (DEF) and one discretionary balanced manager (HIJ). The role of the index tracking manager is to implement the strategic asset allocation at the lowest cost. The role of the specialist property manager is to select the property portfolio both for the purpose of implementing the strategic asset allocation and to beat the property benchmark return by X\% p.a. over the term of the investment mandate. The role of the discretionary balanced manager is to select the non-property, non-liability-driven assets and to beat the benchmark return on each asset class by X\% p.a. over the term of the investment mandate.

\section{The Mandates Given to All Advisors and Managers}

The scheme is advised by KLM Consulting Actuaries Ltd and NOP Investment Advisors Ltd. KLM are ins tructed to conduct triennial asset-liability studies and NOP are instructed to advise on the fund's strategic asset allocation in the light of these studies. Formerly KLM provided both actuarial and investment advice services, but the trustees decided to appoint a separate investment advisor.

The investment performance target for the index tracking manager $(\mathrm{ABC})$ is to generate a tracking error of less than $\mathrm{X} \%$ p.a. on each of the following indices $\mathrm{A}, \mathrm{B}, \mathrm{C}, \ldots$ and operating costs of less than Y\% p.a. over the three-year investment mandate.

The investment performance target for the specialist property manager (DEF) is to beat the D Property Index by X\% p.a. over the three-year investment mandate.

The investment performance target for the discretionary balanced manager is to beat each of the following indices $\mathrm{A}, \mathrm{B}, \mathrm{C}, \ldots$ by $\mathrm{X} \%$ p.a. over the three-year investment mandate.

QRS Performance Measurement Services Ltd measure the performance of the fund on a quarterly basis.

\section{The Nature of the Fee Structures in Place for All Advisors and Managers, and Why This Set of Structures Has Been Selected}

$\mathrm{ABC}$ receives an annual fee of $\mathrm{X} \%$ of the value of the assets that $\mathrm{ABC}$ manages, payable quarterly in arrears. The low fee reflects the low-cost nature of index-tracking.

DEF and HIJ receive an annual fee of X\% of the value of the assets that each manage plus a performance-related bonus of $\mathrm{XX} \%$ of the product of the value of the assets and the return in excess of the benchmark, payable quarterly in arrears. If the excess return is negative during any quarter, the fee payable to the fund manager is reduced accordingly. These performance-related fees reflect the active nature of the investment mandates and provide an appropriate incentive to beat their target without taking on excessive risks. 
KLM, NOP and QRS receive an annual fee of $£ X, £ Y$ and $£ Z$, respectively, payable quarterly in arrears. The fixed fee reflects the commoditised service provided.

\section{- Policy on Selecting Investments}

\section{Need for Diversification of Investments}

The trustees are aware of the role of diversification in helping to reduce the volatility in the overall value of the fund's investments without sacrificing investment performance.

\section{Suitability of Investment Categories Proposed and Individual Investments}

The trustees are also aware of the importance of selecting investments whose returns are highly correlated with fluctuations in the value of the liabilities. Given that the liabilities are denominated in sterling, the trustees are aware that the bulk of the assets will also be denominated in sterling.

\section{How Trustees Have Obtained and Considered Proper Advice Given in Writing by a Suitably Qualified Investment Advisor}

The statement has been agreed by the trustees on the basis of written advice from the investment committee and the scheme actuary following consultation with NOP Investment Advisors Ltd and the employer.

\section{How Often the Trustees Obtain Revised Advice on the Suitability of Investments}

The trustees review the statement at least every three years in the light of each triennial actuarial valuation.

\section{How the Trustees Ensure that the Investment Manager Will Make Decisions in Line with the SIP}

The investment committee monitors compliance with this statement at least annually and obtains confirmation from the investment managers that they have acted in a way that is consistent with the principles.

The Extent (If Any) to Which Social, Environmental and Ethical Considerations are Taken into Account in the Selection, Retention and Realisation of Investments

The trustees pay regard to social, ethical and environmental considerations in the selection, retention and realisation of fund investments to the extent that is consistent with their legal duties to do so. The trustees have adopted a policy of active engagement with those companies in which the fund invests concerning the ethical, environmental and social policies pursued by those companies. The trustees are keen to promote those policies that will both meet best practice in these areas and protect and enhance the value of the fund's investments in those companies.

\section{The Extent (If Any) to Which Rights (Including Voting Rights) Attaching to Investments are Exercised}

The trustees place great emphasis on the proper corporate governance of companies in which the fund invests. The trustees have adopted the principles of the US Department of Labor Interpretative Bulletin on activism. Votes are cast where appropriate on the basis of these principles on resolutions at the general meetings of all UK and overseas companies in which the fund has investments. 


\section{The Need to Respect the Scheme's Funding Standard}

At the last triennial valuation as at 31 March 20XX, the scheme's funding level exceeded the scheme's chosen funding standard as specified in the Occupational Pension Schemes (SchemeSpecific Funding Standard and Actuarial Valuations) Regulations 200X. The trustees aim to maintain a funding level above the scheme's funding standard on a continuous basis.

\section{- Policy on Managing Investments and Monitoring Performance}

\section{Kinds of Investments}

- $\quad$ Listed securities

Investment managers are permitted to invest, without the prior approval of the chairman of the investment committee, in investment-grade securities listed on a recognised or designated investment exchange. Investment in non-investment-grade securities listed on a recognised or designated investment exchange require the prior approval of the chairman of the investment committee.

- Unlisted securities and private equity

Investment managers are permitted to invest, subject to the prior approval of the chairman of the investment committee, in unlisted securities and private equity.

- Stock lending

The trustees are authorised by the scheme rules to participate in stock lending. Any stock lending programme in which the fund participates must provide for all loans to be fully pre-collateralised and be approved by the investment committee on legal advice.

- Derivatives

The discretionary balanced manager is permitted to use derivatives solely for the purposes of efficient portfolio management and the reduction of risk.

\section{- Underwriting}

The discretionary balanced manager is permitted to underwrite issues provided it is prepared to hold all the stock which it underwrites.

\section{Balance Between Different Kinds of Investments}

The investment committee sets guidelines for the strategic asset allocation of the total fund within which the investment managers, taken as a whole, are required to operate. The investment committee reviews these guidelines quarterly. The guidelines set for strategic asset allocation are consistent with the investment committee's views on the appropriate balance between risk and return and have due regard to the liabilities of the scheme.

The total investment in each broad asset class is determined by the investment advisor under its delegated authority within the above guidelines set by the investment committee after consideration of: 
- the scheme's chosen funding standard as specified in the Occupational Pension Schemes (Scheme-Specific Funding Standard and Actuarial Valuations) Regulations 200X, and

- long-term funding solvency and the employer's willingness to support the pension scheme in the long term.

\section{Risk}

\section{General}

There are two key risks that must be taken into account:

- surplus risk: the risk of a shortfall in the value of the pension scheme's assets in relation to its liabilities

- contribution risk: the volatility over time of contributions into the scheme

These risks are managed by choosing the contribution rate and strategic asset allocation to minimise the following Loss function $=$ Surplus Risk $+\lambda \times$ Contribution Risk, where $\lambda$ shows the relative importance of minimising contribution risk in comparison with minimising surplus risk. The trustees have determined that the employer values a stable pattern of contributions into the scheme. Surplus risk is minimised by choosing assets which are highly correlated with the growth over time in liabilities.

Individual securities are included in the pension fund on account of the high correlations between changes in their values and the growth in liabilities. However, these individual securities are also risky in their own right since they represent claims on risky investments that can fail.

\section{Listed securities}

Risk will be managed by requiring fund managers to hold a diversified spread of investments that are reviewed on a regular basis by the investment committee.

In addition, the following constraints will apply:

- No more than $5 \%$ of the total fund by market value can be invested in one company (at the date of purchase)

- No more than $10 \%$ of the total fund by market value can be invested in companies in any one industry (at the date of purchase)

- No more than 5\% of the total fund by market value can be invested in unlisted securities or private equity (at the date of purchase); all such investments require the prior approval of the chairman of the investment committee.

- No more than $10 \%$ of the market capitalisation of any one company (at the date of purchase)

- No more than $2 \%$ of the total fund can be invested in cash form with any one financial institution. 
The fund's assets are held by an independent custodian.

\section{Stock lending}

The trustees participate only in stock lending programmes with a high degree of risk mitigation. The trustees have concluded that the risks associated with such programmes are not qualitatively different from those of other market operations and are justified in the light of the return to the scheme in terms of the annual stock lending fees generated.

\section{Derivatives}

The current limit is $10 \%$ of funds under management for the discretionary balanced manager.

\section{Assumed returns on investments}

The assumed real returns on investments are given in the last column of Table B.1.

Table B.1: Benchmark Asset Allocation and Assumed Real Investment Returns

\begin{tabular}{lccr} 
& \multicolumn{2}{c}{ Asset Allocation } & \\
\cline { 2 - 3 } Asset Class & Actual 31 March 200X & Benchmark & Assumed Real Return \\
\hline UK Large Cap Listed Equities & $60 \%$ & $45 \%$ & $4 \%$ \\
UK Small Cap Listed Equities & $7 \%$ & $1 \%$ & $4 \%$ \\
UK Unlisted and Private Equity & $1 \%$ & $0.5 \%$ & $4 \%$ \\
International Equities & $2 \%$ & $0.5 \%$ & $4 \%$ \\
UK Index-Linked Bonds & $13 \%$ & $15 \%$ & $2.5 \%$ \\
UK Fixed-Income Bonds & $8 \%$ & $5 \%$ & $2.5 \%$ \\
International Fixed-Income & $3 \%$ & $10 \%$ & $2.5 \%$ \\
Bonds & $3 \%$ & & \\
Property & $3 \%$ & $15 \%$ & $2.5 \%$ \\
Cash & $\mathbf{1 0 0 \%}$ & $\mathbf{1 0 0 \%}$ & $1 \%$ \\
& & & $\mathbf{2 . 4 \%}$ \\
\hline
\end{tabular}

Source: NOP Investment Advisors Ltd

These are based on an examination of historical experience over the last 50 years. Historically, the real returns on some asset categories, such as equities, have been much higher than the returns that have been assumed in the table. However, the investment advisors have advised that such high returns cannot be expected in the future. Increasing global competition will tend to lower equity returns in all countries. The advisors believe that the real returns on the asset classes that can be expected in future are those given here.

The real return on equities is expected to be $4 \%$ and this return is expected to exceed that on all other assets, except cash, by 1.5 percentage points (this difference is known as the 'equity risk premium'). The real return on property and bonds is expected to be $2.5 \%$, while the return on cash is expected to be $1 \%$. These figures form the basis of the asset-liability study.

\section{The Fund's Planned Asset Allocation Strategy and How the Strategy Has Been Arrived At}

The second column of Table B.1 shows the actual asset allocation of the pension fund as at 31 March 200X. This asset allocation is heavily biased towards equities, especially UK equities, and bonds, especially index-linked bonds. This asset allocation is currently very similar to that of other pension funds in the UK. 
In accordance with the Occupational Pension Schemes (Scheme-Specific Funding Standard and Actuarial Valuations) Regulations 200X, the pension scheme has introduced a scheme-specific funding standard. This requires the pension fund to invest in assets that match as closely as possible the liabilities of the scheme in terms of key features of the liabilities, such as the way that they change over time in response to earnings growth, changing interest rates and demographic factors.

Following the introduction of these regulations, the scheme actuary, on the advice of NOP Investment Advisors, has established a new benchmark asset allocation which is listed in the third column of Table B.1. The new benchmark involves a radical switch away fom domestic equities and bonds towards property, cash and international bonds. This switch will take place over the next 12 months.

The funds will be allocated to the investment managers in the following proportions:

- $\mathrm{ABC}$ (index tracking) $-75 \%$

- $\mathrm{DEF}$ (specialist property) - $15 \%$

- $\quad$ HIJ (discretionary balanced) $-10 \%$

These proportions fluctuate as a result of stock market movements and cash allocation.

Cash flows from contributions and investment income are normally allocated to the investment managers in the same proportions:

- $\mathrm{ABC}$ (index tracking) $-75 \%$

- $\mathrm{DEF}$ (specialist property) $-15 \%$

- $\mathrm{HIJ}$ (discretionary balanced) $-10 \%$

The cash allocation is reviewed and approved by the investment committee on a quarterly basis.

If there are significant departures from the asset allocation recommended each quarter by the investment committee, the investment specialists on the investment committee will be notified. In this way market movements and asset allocation shifts are monitored and any desired changes are approved by the chairman of the investment committee after consultation with the investment specialists on the investment committee and NOP Investment Advisors.

\section{Realisation of Investments}

The asset-liability study indicates that the scheme has a below-average maturity profile and a likely positive cash flow for the next 10 years. This makes it unlikely that the fund will need to realise investments to meet liabilities in the short term.

\section{Monitoring Performance}

The performance of the fund and of each investment manager is measured quarterly by QRS Performance Measurement Services Ltd. The performance of the investment managers and the fund is reported quarterly to the investment committee. 
The internal auditor and chief investment officer visit the investment managers to check the quality and effectiveness of procedures on a regular basis.

The presentation of investment performance data is in line with the UK Investment Performance Standard (UKIPS).

Reasons for Any Departure from the Principles

There are currently no departures from the SIP. 


\section{Appendix C: Illustrative Transparency Statement}

\section{asset Values and the Current Asset Allocation}

The current value of the assets in your pension fund (as of 31 March 200X) is £X. The second column of Table C. 1 shows how these assets are currently allocated to the asset classes given in the first column. Your pension fund is currently invested very heavily in equities, especially UK equities, and bonds, especially index-linked bonds. This asset allocation is currently very similar to that of other pension funds in the UK.

\begin{tabular}{lrr}
\hline $\begin{array}{l}\text { Table C.6: Current and Future Asset Allocations of Your Pension } \\
\text { Fund }\end{array}$ & \\
Asset Class & Current & Future \\
\hline UK Large Cap Listed Equities & $60 \%$ & $45 \%$ \\
UK Small Cap Listed Equities & $7 \%$ & $1 \%$ \\
UK Unlisted and Private Equity & $1 \%$ & $0.5 \%$ \\
International Equities & $2 \%$ & $0.5 \%$ \\
UK Index-Linked Bonds & $13 \%$ & $15 \%$ \\
UK Fixed-Income Bonds & $8 \%$ & $5 \%$ \\
International Fixed-Income & $3 \%$ & $10 \%$ \\
Bonds & $3 \%$ & $15 \%$ \\
Property & $3 \%$ & $8 \%$ \\
Cash & $\mathbf{1 0 0 \%}$ & $\mathbf{1 0 0 \%}$ \\
&
\end{tabular}

Source: NOP Investment Advisors Ltd

\section{- Liabilities}

The liabilities of the fund are the future pension payments to you and other members of the scheme. The Scheme Actuary has placed a value of $£ Y$ on the scheme liabilities. In order to determine this value, the Scheme Actuary had to make the following assumptions:

- Members' contributions: $6 \%$ of their pensionable pay.

- Employer's contributions: $14 \%$ of pensionable pay.

- Earnings growth: $4.5 \%$ a year (or $2 \%$ above inflation).

- Deferred pension increases before retirement : $2.5 \%$ a year.

- Pension increases in retirement : $2.5 \%$ a year.

- Discount rate for liabilities: $5 \%$ a year (or $2.5 \%$ above inflation).

- Demographic assumptions: Mortality of scheme members is assumed to be in line with that of the standard mortality tables PMA92 (for men) and PFA92 (for women) published by the Faculty and Institute of Actuaries, projected as appropriate for the year of birth of the member.

- Scheme size: there is no change over time in the number of active members of the scheme. 
These assumptions are all the same as used for the last assessment.

The Scheme Actuary has made an assessment of the likely level of pension payments in future years on the basis of the above assumptions, together with more detailed assumptions on matters such as the proportions of company employees leaving and retiring from the scheme at each age and the pattern of new entrants to the scheme. More details on the actuarial assessment are available from the Secretary to the Trustees.

\section{- Planned Future Contributions}

As explained below, the Trustees are planning major changes to your pension fund's asset holdings. However, on the basis of the investment performance that the Trustees' investment advisors expect to achieve following the change in asset holdings, there will be no need to change the contributions into your scheme. The member's contribution rate will remain fixed at $6 \%$ of pensionable pay and the employer's contribution rate will remain fixed at $14 \%$ of pensionable pay.

\section{- Planned Asset Allocation for the Following Years}

Recent legislation has required your pension scheme to introduce a scheme-specific funding standard. This means that your pension fund must invest in assets that match as closely as possible the liabilities of the scheme in terms of key features of the liabilities, such as the way that they change over time in response to earnings growth, changing interest rates and demographic factors. This in turn means that your pension fund's assets must be chosen specifically to suit your scheme, irrespective of the way in which other pension funds invest.

Following the introduction of this legislation, the Scheme Actuary has established a new asset allocation suitable for your scheme. This is given in the third column of Table C.1. The figures indicate a radical switch away from domestic equities and bonds towards property, cash and international bonds. This switch will take place over the next 12 months.

\section{Assumed Returns and Volatilities on Assets}

The assumed returns and assumed volatilities of those returns for each asset class sufficient to meet the liabilities are presented in Table C.2.

The real return means the return after taking inflation into account.

Standard deviation measures the riskiness of a particular asset class. The simplest way to explain standard deviation is in terms of the so-called ' $1-$ in- 6 rule'. There is a 1 -in- 6 chance that the realised return on an asset in a particular year will be less than one standard deviation below the mean return and there is a 1-in- 6 chance that the realised return on an asset in a particular year will be more than one standard deviation above the mean return. So, for example, there is a 1-in-6 chance that the realised real return on property over the course of the next year will be below $-5 \%$ and a $1-$ in- 6 chance that it will be above $15 \%$. 


\begin{tabular}{lccc}
\hline Table C.2: Assumed Returns and Volatilities on Assets & \\
Asset Class & $\begin{array}{c}\text { Real } \\
\text { Return }\end{array}$ & $\begin{array}{c}\text { Standard } \\
\text { Deviation* }\end{array}$ & $\begin{array}{c}\text { Correlation with } \\
\text { Liabilities* }\end{array}$ \\
\hline UK Large Cap Listed Equities & $4 \%$ & $27 \%$ & $-5 \%$ \\
UK Small Cap Listed Equities & $4 \%$ & $32 \%$ & $-8 \%$ \\
UK Unlisted and Private Equity & $4 \%$ & $38 \%$ & $-35 \%$ \\
International Equities & $4 \%$ & $21 \%$ & $-5 \%$ \\
UK Index-Linked Bonds & $2.5 \%$ & $7 \%$ & $-7 \%$ \\
UK Fixed-Income Bonds & $2.5 \%$ & $14 \%$ & $-34 \%$ \\
International Fixed-Income & $2.5 \%$ & $17 \%$ & $-2 \%$ \\
Bonds & & & \\
Property & $2.5 \%$ & $10 \%$ & $36 \%$ \\
Cash & $1 \%$ & $2 \%$ & $21 \%$ \\
\hline
\end{tabular}

Source: Table 1 (estimates for UK small cap listed equity and UK unlisted and private equity)

${ }^{+}$Return in excess of inflation * See Appendix D

Correlation measures the degree to which two variables move together. The degree of correlation lies between -1 and +1 . Your pension fund is planning to invest in assets with the highest correlations with the growth in the fund's pension liabilities, which, in turn, is related to earnings growth. As you can see from the last column of Table C. 2 this means property, cash and international fixed-income bonds.

\section{- Justification of Assumptions Used}

In the interests of transparency, the Trustees must provide you with an explanation of the reasonableness of both the investment returns assumed and the asset allocation in the light of the circumstances of the fund and of the employer, XYZ Ltd.

Table C.2 was prepared by the Trustees' investment advisors. It was based on asset performance over the last half century, but also took into account factors that the investment advisors thought would be important in the future.

Table C. 3 shows the actual asset performance over the last half century. Historically, the real returns on some asset categories, such as equities, have been much higher than the returns that have been assumed in Table C.2. However, the Trustees' investment advisors have advised that such high returns cannot be expected in the future. Increasing global competition will tend to lower equity returns in all countries. The advisors believe that the real returns on the asset classes that can be expected in future are those given in the second column of Table C.2. The real return on equities is expected to be $4 \%$ and this return is expected to exceed that on all other assets, except cash, by 1.5 percentage points (this difference is known as the 'equity risk premium'). The real return on property and bonds is expected to be $2.5 \%$, while the return on cash (which means money market instruments, such as Treasury bills, rather than loose change) is expected to be $1 \%$.

The investment advisors have advised that the historical standard deviations and correlations with liabilities given in Table C. 3 should be used in the future. They believe the world's stock markets are entering a period of uncertainty in the near term that justifies maintaining the risk factors (standard deviations) on all asset classes at their historical levels, despite lowering the anticipated returns on some of the more volatile asset classes. 


\begin{tabular}{lccc}
\hline $\begin{array}{l}\text { Table C.3: Historical Performance of Asset Classes Over the Last Fifty } \\
\text { Years }\end{array}$ & $\begin{array}{c}\text { Mean } \\
\text { Real Return }\end{array}$ & $\begin{array}{c}\text { Standard } \\
\text { Deviation* }\end{array}$ & $\begin{array}{c}\text { Correlation with } \\
\text { Liabilities* }^{*}\end{array}$ \\
Asset Class & $10 \%$ & $27 \%$ & $-5 \%$ \\
\hline UK Large Cap Listed Equities & $6 \%$ & $32 \%$ & $-8 \%$ \\
UK Small Cap Listed Equities & $12 \%$ & $38 \%$ & $-35 \%$ \\
UK Unlisted and Private Equity & $9 \%$ & $21 \%$ & $-5 \%$ \\
International Equities & $4 \%$ & $7 \%$ & $-7 \%$ \\
UK Index-Linked Bonds & $2 \%$ & $14 \%$ & $-34 \%$ \\
UK Fixed-Income Bonds & $2 \%$ & $17 \%$ & $-2 \%$ \\
International Fixed-Income & & & \\
Bonds & $5 \%$ & $10 \%$ & $36 \%$ \\
Property & $1 \%$ & $2 \%$ & $21 \%$ \\
Cash &
\end{tabular}

Source: Table 1 (estimates for UK small cap listed equity and UK unlisted and private equity)

${ }^{+}$Return in excess of inflation * See Appendix D

The Trustees' investment advisors believe that it is sensible to use rather conservative estimates of future performance. They also recommend examining long periods (i.e., 50 years) of previous performance before reaching their conclusions about future performance. Other pension funds take into account historical performance data for periods as short as 20 years, but the investment advisors believe that the last 20 years was such an exceptionally bullish period in stock market history that this period by itself would provide a very inaccurate indicator of future performance. Accordingly and given the very long time frame of pension fund investment, the investment advisors prefer to examine longer periods of performance data.

Your pension fund is about to implement a major shift in its asset allocation away from equities and domestic bonds and towards property, cash and international bonds. This switch is based on an asset-liability study conducted by the Scheme Actuary with advice from the investment advisor, the purpose of which was to find asset classes that minimised both:

- the likelihood of a shortfall in the value of the pension fund compared with the value of the liabilities and

- the volatility of the employer's contributions into the scheme.

The best asset classes for achieving this are those that are most highly correlated with the growth rate over time in your earnings, since this is the most important single factor determining the growth rate in your pension scheme's liabilities. In addition, your employer wants to reduce the risk of having to put large sums of money into your pension fund in order to keep it solvent.

The Trustees believe that, with the asset allocation given in the last column of Table C.1 and with total contributions of $20 \%$ of pensionable earnings, your pension fund is both secure and adequately funded.

\section{- Implications of the Volatilities of Investment Values}

Although the Trustees believe that your pension fund is both secure and adequately funded, the future can still bring surprises. Three key risks are that:

- assets underperform the returns assumed in the second column of Table C.2 
- asset return volatility is greater than assumed in the third column of Table C.2, and

- correlations between asset returns and liability growth are lower than assumed in the fourth column of Table C.2.

Sustained underperformance in equity would have serious consequences for the funding adequacy of your pension scheme. For example, the Scheme Actuary has estimated that if the real return on equity fell from the $4 \%$ assumed to $3 \%$, the funding level would fall to $95 \%$ after 10 years. To restore the funding level to $100 \%$ would require the employer to make a deficiency payment into your pension fund equal to $6 \%$ of your current earnings.

Similarly, increases in asset return volatility would increase the likelihood of the employer having to make deficiency payments as would lower correlations between asset returns and liability growth.

Nevertheless the Trustees believe that the asset allocation that your pension fund is planning to switch into is the best one for minimising the risk of serious underperformance. The Trustees will continuously monitor your fund's performance and make any changes necessary to the asset allocation in response to changing circumstances in order to maintain a high degree of security in your pension scheme. 


\section{Appendix D: Standard Deviation, Value-at-Risk and Correlation}

Standard deviation is a commonly used measure of the volatility or risk of a variable. It measures the extent to which the dispersion of a random variable is concentrated around its mean or average value: if the degree of concentration is high, so that realised values of the variable are always close to the mean, then the standard deviation will be low, and vice versa.

The formula for calculating the standard deviation of $N$ values of a variable $x_{i}$ is as follows:

where

$$
\text { Standard deviation }=\frac{\sum_{i=1}^{N}\left(x_{i}-\bar{x}\right)^{2}}{N-1}
$$

$$
\begin{aligned}
& x_{i}=\text { the } i^{t h} \text { value (out of a total of } N \text { ) of the variable } \\
& \bar{x}=\frac{\sum_{i=1}^{N} x_{i}}{N}=\text { the mean or average of the set of } N \text { variables } \\
& \sum_{i=1}^{N}=\text { sum over a set of variables from } 1 \text { to } N .
\end{aligned}
$$

Standard deviation is best illustrated in terms of the 1-in-6 and 1-in-40 rules as shown in Chart D.1. Chart D.1 shows the familiar bell-shaped curve of the standard normal distribution which has a mean of 0 and a standard deviation of 1 .

Suppose that a time-varying random variable is generated by this distribution with annual realisations of the variable. There is then a 1-in- 6 chance that the realised value of this variable in a particular year will be less than one standard deviation below the mean. In other words the area beneath the curve to the left of -1 in the figure is $1 / 6^{\text {th }}$ of the total area under the curve. The figure -1 is also sometimes known as the 1-in-6 value-at-risk. Another way of expressing this is that in 1 year in 6 , we expect to see values less than one standard deviation below the mean. Similarly, there is a 1-in-40 chance that the value of the variable in a particular year (or in one year out of every 40) will be less than two standard deviations below the mean, i.e., less than -2 in Chart D.1 (this figure is also sometimes known as the 1-in-40 value-at-risk).

Correlation measures the degree to which two variables move together. The degree of correlation lies between -1 and +1 . If two variables are perfectly positively correlated (with a correlation coefficient of +1 ), they will move exactly in line with each other: for every one unit rise in one of the variables there will be precisely a one-unit rise in the other variable. If two variables are perfectly negatively correlated (with a correlation coefficient of -1 ), they will move in exactly opposite directions: for every one unit rise in one of the variables there will be precisely a one unit fall in the other variable. If two variables have a correlation coefficient of zero, they are said to be uncorrelated: the movement of one variable is unrelated to the movement in the other variable. Correlation coefficients lying between 0 and 1 indicate positive but less than perfect correlation between pairs of variables, the weaker the positive correlation the closer the coefficient will be to 0 and vice versa. A similar result holds for negative correlation coefficients lying between 0 and 1 .

The formula for calculating the correlation between $N$ pairs of values of variables $x_{i}$ and $y_{i}$ is as follows: 
Correlation coefficient $=\frac{\sum_{i=1}^{N}\left(x_{i}-\bar{x}\right)\left(y_{i}-\bar{y}\right)}{\sqrt{\sum_{i=1}^{N}\left(x_{i}-\bar{x}\right)^{2} \sum_{i=1}^{N}\left(y_{i}-\bar{y}\right)^{2}}}$

Chart D.1: The 1-in-6 and 1-in-40 Values -at-Risk with the Standard Normal Distribution

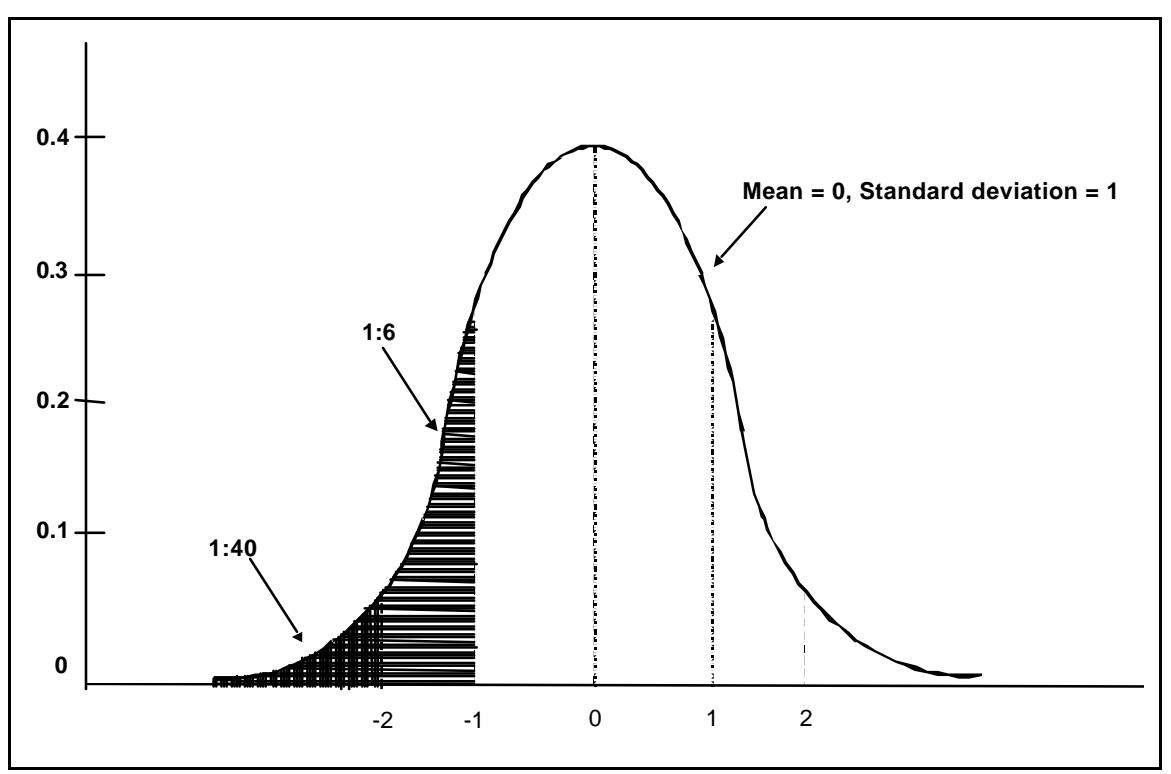

Source: Mood, Graybill and Boes (1974, Fig. 9, p. 108) 


\section{Appendix E: The Optimal Strategic Asset Allocation}

The exercise of minimising the loss function in (4) has to be conducted on a regular basis (annually or, more commonly, triennially). This is to ensure both that the scheme is always adequately funded (i.e., Surplus $=0$ ) and that the strategic asset allocation always matches the volatility of the liabilities (Surplus Risk is minimised).

In the case where the pension fund is planning to have neither a surplus nor a deficit at the end of the control period and where the standard deviations of the retention, annuity and discount factors in (6) are zero, the asset holdings that minimise the loss function in (4) are given by:

$$
\mathbf{q}(t)=[\mathbf{S}+\lambda \mathbf{O}]^{-1} \mathbf{z}(t)
$$

where

- $\quad \mathbf{z}(t)=H(t) W(t) \mathbf{?}+\lambda(L(t+1)-\gamma W(t))(\mathbf{1}+\boldsymbol{\mu})$

- $\quad H(t)=D(t+1, T) a(t) A(T)(T-t)(1+g)^{T-(t+1)}$

- $\quad L(t+1)=$ liabilities at age $t+1$

- $\gamma=$ contribution rate as a proportion of current earnings $W(t)$ necessary to give a zero surplus at the end of the control period

- $\mathbf{q}(t)=$ a vector of $N$ asset holdings for a pension scheme member aged $t$, with typical element $q_{i}(t)$

- $(\mathbf{1}+\boldsymbol{\mu})=$ a vector of $N$ gross expected returns on the above asset holdings with typical element $\left(1+\mu_{i}\right)$

- $\quad ?$ = a vector of $N$ covariances between the above asset holdings and earnings growth with typical element $\rho_{i}$

- $\quad \mathbf{S}=$ an $N$ x $N$ matrix of covariances between the returns on the asset holdings with typical element $\sigma_{i j}$

- $\mathbf{O}=$ an $N$ x $N$ matrix of gross expected return cross-products with typical element $\left(1+\mu_{i}\right)\left(1+\mu_{j}\right)$.

The optimal portfolio is biased towards assets that are highly correlated with earnings (?), and biased against volatile assets (as measured by $\mathbf{S}$ ).

It should be clear from (2) that as the pension fund matures (i.e., as the pension scheme member approaches retirement), the revaluation, retention and discount factors, $R(t, T), P(t, T)$ and $D(t, T)$, converge in size towards unity and so the value of the liabilities becomes dominated by the size of the annuity factor, $A(T)$. In other words, whatever the initial asset allocation of the pension fund, 
the surplus risk minimisation exercise will indicate that the pension fund as it matures should move its asset allocation towards the asset class that matches most closely the pension fund's obligation to pay annuities, namely index-linked bonds. Samuelson (1989) has called this dynamic investment strategy age-phasing and it is now more commonly known as lifestyle fund management: the strategy is examined in more detail in Blake (1998a). 